\title{
THE ACTIVE MOVEMENT SCALE: AN EVALUATIVE TOOL FOR INFANTS WITH OBSTETRICAL BRACHIAL PLEXUS
}

\author{
PALSY
}

by

\section{Christine Glenn Curtis}

A thesis submitted in conformity with the requirements for the degree of Masters of Science

Graduate Department

Institute of Medical Science

University of Toronto

c) Copyright by Christine Glenn Curtis, 2000 
National Library

of Canada

Acquisitions and Bibliographic Services

395 Wellington Street Ottawa ON K1A ON4 Canada
Bibliothèque nationale

du Canada

Acquisitions et services bibliographiques

395, rue Wellington

Ottawa ON K1A ON4

Canada
The author has granted a nonexclusive licence allowing the National Library of Canada to reproduce, loan, distribute or sell copies of this thesis in microform, paper or electronic formats.

The author retains ownership of the copyright in this thesis. Neither the thesis nor substantial extracts from it may be printed or otherwise reproduced without the author's permission.
L'auteur a accordé une licence non exclusive permettant à la Bibliothèque nationale du Canada de reproduire, prêter, distribuer ou vendre des copies de cette thèse sous la forme de microfiche/film, de reproduction sur papier ou sur format électronique.

L'auteur conserve la propriété du droit d'auteur qui protège cette thèse. $\mathrm{Ni}$ la thèse ni des extraits substantiels de celle-ci ne doivent être imprimés ou autrement reproduits sans son autorisation. 


\title{
ABSTRACT
}

\section{The Active Movement Scale: An Evaluative Tool For Infants With Obstetrical} Brachial Plexus Palsy

\author{
Christine Glenn Curtis \\ Masters of Science \\ Institute of Medical Science \\ University of Toronto \\ 2000
}

Objective: To determine the reliability of the Active Movement Scale for the evaluation of infants with obstetrical brachial plexus palsy.

Methods: Two complementary studies were conducted. Part A was an inter-rater reliability study in which two physiotherapists, experienced in using the Active Movement Scale, assessed 63 infants with obstetrical brachial plexus palsy. Part B examined the dispersion of Active Mlovement Scale scores of infants with obstetrical brachial plexus palsy who were evaluated by trained physiotherapists.

Results: The overall quadratic weighted kappa analysis in Part A demonstrated that the rater's scores were in the highest level of agreement $\left(\mathrm{K}_{\text {quad }}=0.89\right)$. Part $\mathrm{B}$ established that the variability of scores due to rater factors was low compared with patient factors and that variation in scores due to rater experience was minimal.

Conclusions: The Active Movement scale is a reliable tool for the evaluation of infants up to one year of age with obstetrical brachial plexus palsy when raters are trained in the use of the scale. 


\section{ACKNOWLEDGEMENTS}

I am extremely grateful to numerous people for their support and encouragement during the course of this research. The members of my Programme Advisory committee including Dr. Rosemary Tannock. Dr. David Andrews and Dr. Chantal Graveline have each provided expert guidance and unique perspectives to this project and have made this endeavor a rich and gratifying learning experience.

Particular, heartfelt gratitude is extended to Dr. Howard Clarke as a committee member and beyond for his dedication to this work and his enthusiastic support of all my ventures. His insights and friendship are appreciated.

The Division of Plastic Surgery, the Department of Rehabilitation Services and the Research Institute at The Hospital for Sick Children were especially supportive of this project. My colleague Wendy Barden provided superlative assistance in data collection in Part A of this study and her friendship with that of Karen Klar was enormously helpful throughout the course of this work.

I am indebted to the many families of children with obstetrical brachial plexus injuries as well as the physiotherapists who gave their time to participate in this study. Without their interest and commitment this research would not have been possible. 
Acknowledgment is given to Lippincott, Williams \& Wilkins (428 East, Preston St., Baltimore, MD, 21202) for permission to reproduce Figure 6-24, page 650 in Clinically Oriented Anatomy (second edition) by K.L. Moore, 1985.

The WB Saunders Company (Harcourt Brace Jovanovich Inc., The Curtis Center, Independence Square West. Philadelphia, Pennsylvania, 19106) is acknowledged for reproduction of Mallet's Classification, page 579 in The Hand by Raoul Tubiana. 1993.

J. Richard Landis and Gary G. Koch are acknowledged for reproduction of Agreement Measures for Categorical Data, page 165 in The Measurement of Observer Agreement for Categorical Data, Biometrics 1977;33:159-174 (permission pending).

Acknowledgement is also given to Lucie Chapek, M.D. et al. for reproduction of Table II, page 1556 from Neuroma-In-Continuity Resection: Early Outcome in Obstetrical Brachial Plexus Palsy in Plastic and Reconstructive Surgery 1998;102:15551562 (permission pending).

David Chwei-Chin Chuang, M.D. et al. are acknowledged for reproduction of Table III, page 683 in A New Evaluation System to Predict the Sequelae of Late Obstetric Brachial Plexus Palsy, Plastic and Reconstructive Surgery 1998;101:673-685 (permission pending). 
Gloria Eng M.D. et al. are acknowledged for reproduction of Tables 2 and 4 on pages 885 and 887 in, Obstetrical Brachial Plexus Palsy (OBPP) Outcome With Conservative Management, Muscle \& Nerve 19:884-91;1996 (permission pending).

Unlike most things in science, the unconditional love and support of my husband Len and my children Mike and Ryan cannot be measured. I will be forever grateful tor the encouragement and sacrifice my tamily has offered throughout this work and always. 
TABLE OF CONTENTS:

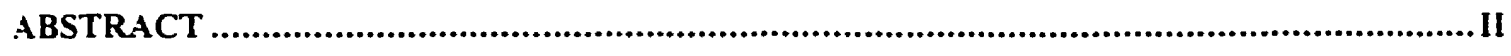

ACKNOWLEDGEMENTS.................................................................................................II

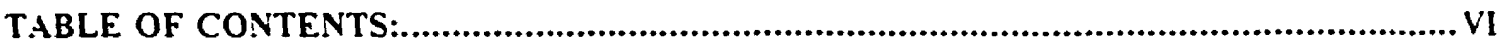

LIST OF TABLES ............................................................................................................ VIII

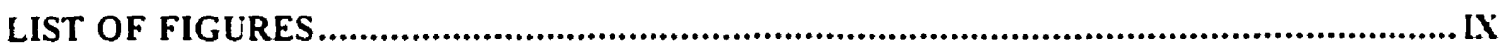

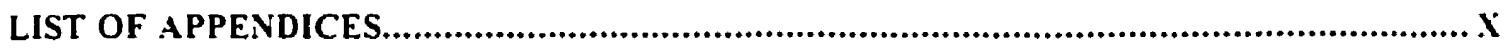

LIST OF ABBREVIATIONS.............................................................................................

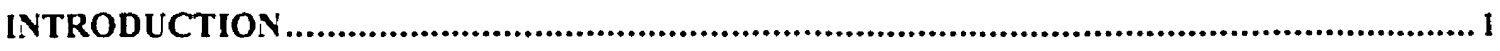

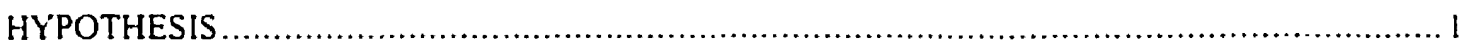

OBJECTIVES

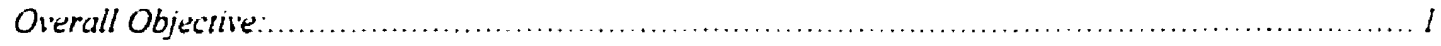

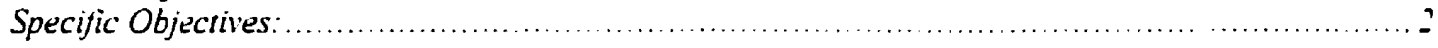

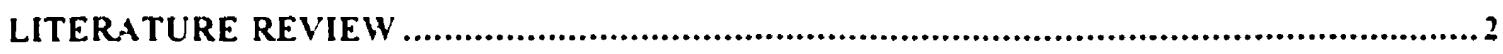

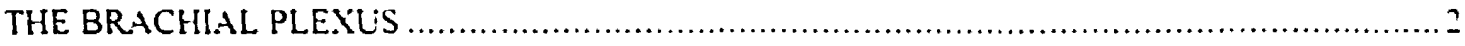

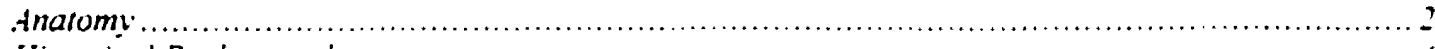

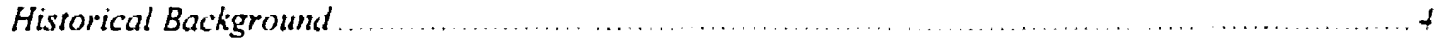

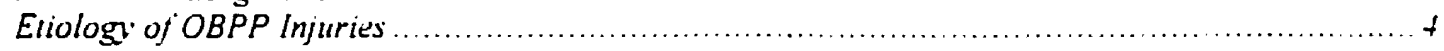

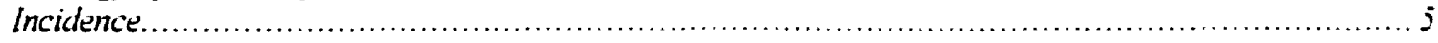

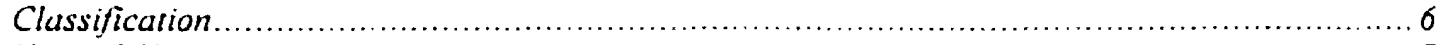

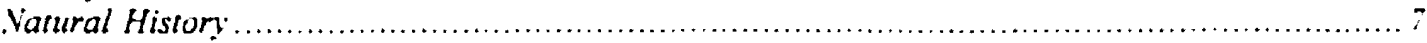

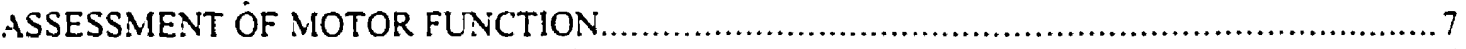

British Medical Research Council Scale ..........................................................

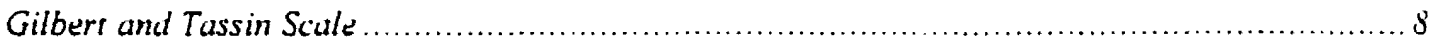

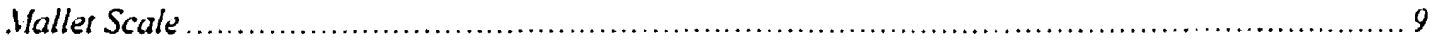

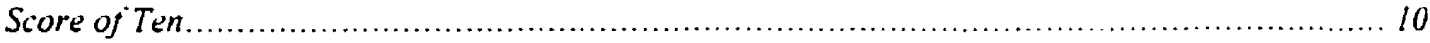

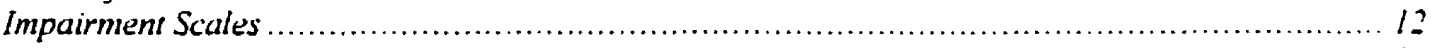

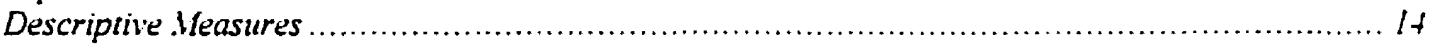

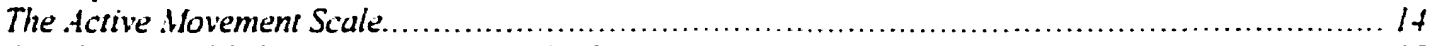

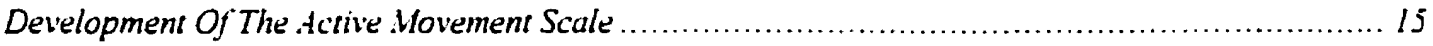

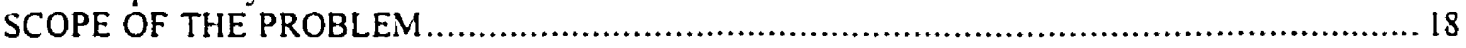

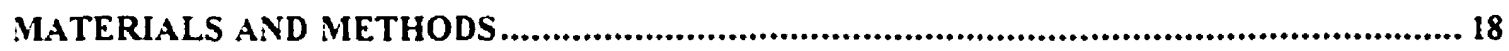

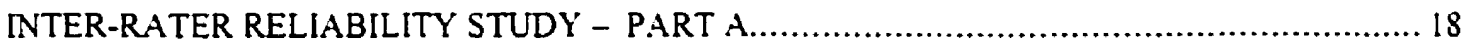

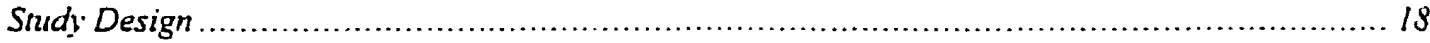

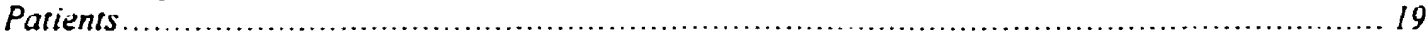

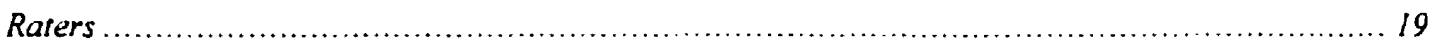

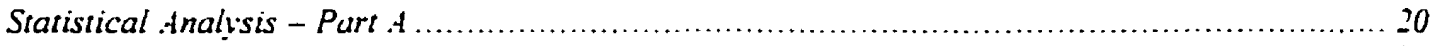

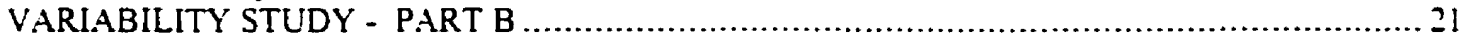

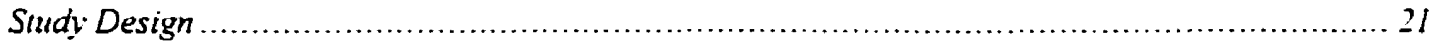

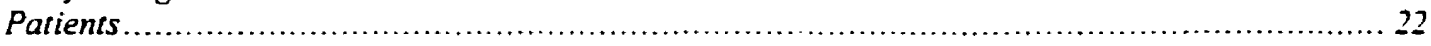

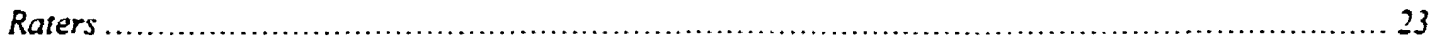

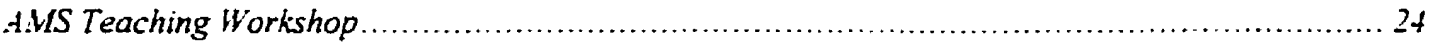

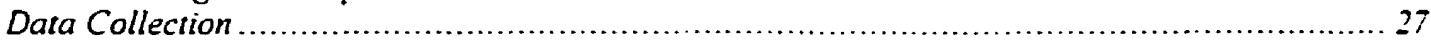

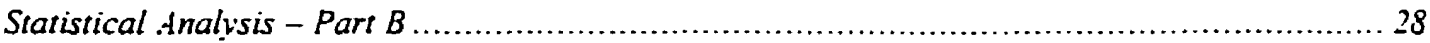




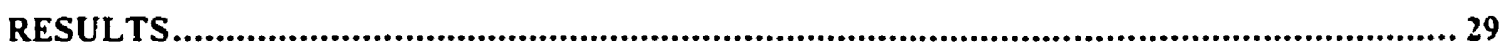

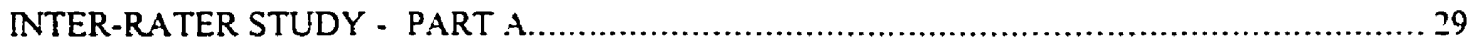

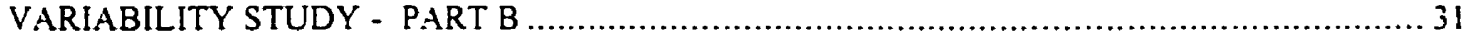

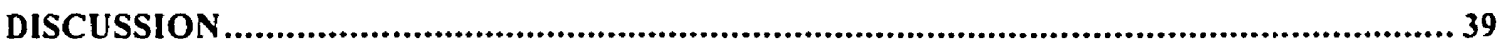

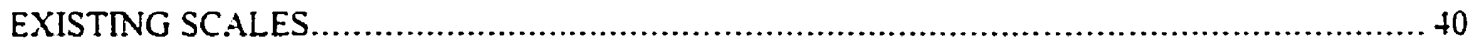

. Medical Research Council Scale ........................................................................... 40

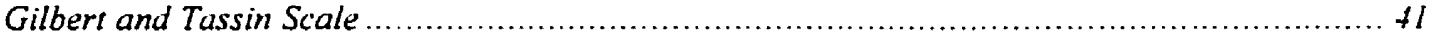

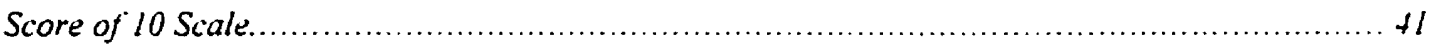

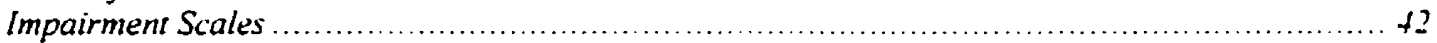

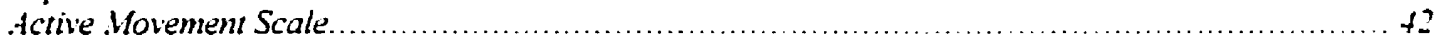

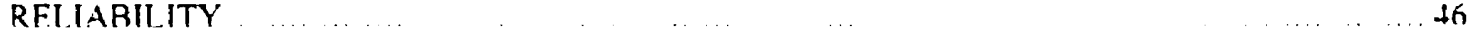

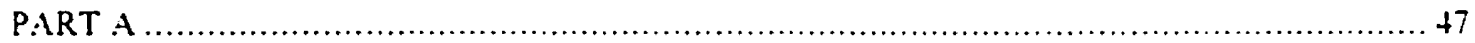

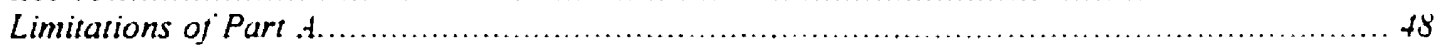

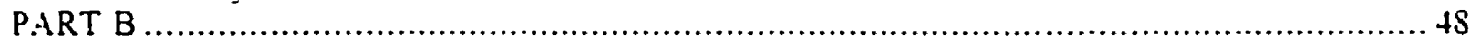

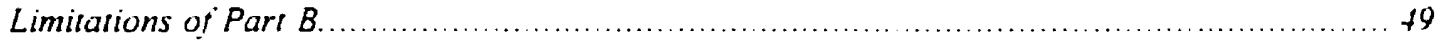

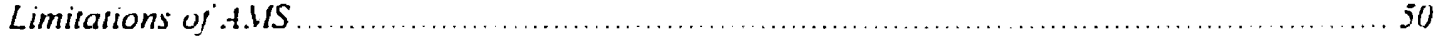

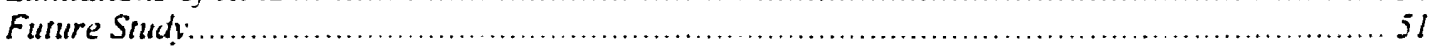

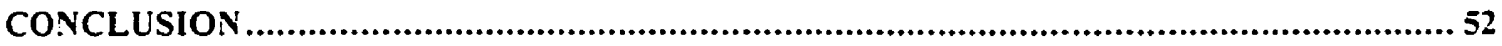

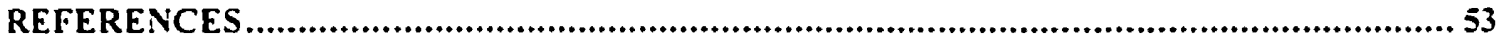

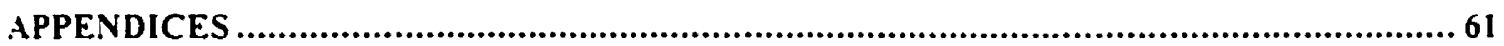

APPENDIX 1: GUIDELINES FOR USE Of THE ACTIVE MUVEMENT SCALE $\ldots \ldots \ldots \ldots \ldots \ldots \ldots \ldots \ldots \ldots \ldots \ldots$

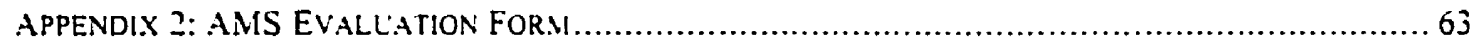

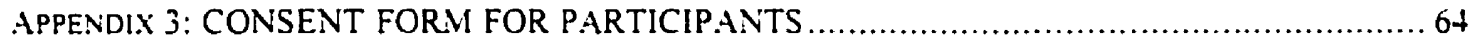

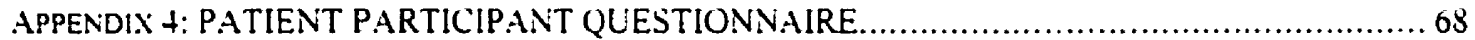

APPENDIX 5: CONSENT FORM FOR HEALTH CARE PROFESSIONALS $\ldots \ldots \ldots \ldots \ldots \ldots \ldots \ldots \ldots . \ldots 9$

APPENDIX 6: R.ATER QUESTIONNAIRE ............................................................... 73 


\section{LIST OF TABLES}

Table I British Medical Research Council system of manual muscle Page 8 testing

$\begin{array}{lll}\text { Table } 2 & \text { Gilbert and Tassin system of muscle grading } & \text { Page } 9\end{array}$

Table 3 Score of 10 relationship between early and late obstetric Page 11 brachial plexus palsy

Table + Impairment rating scale for obstetrical brachial palsy patients Page 13 on initial exam

Table 5 Impairment rating tor brachial plexus palsy patients on Page 13 follow up

Table 6 Active Movement Scale Page 15

Table 7 Agreement Measures For Categorical Data Page 21

Table 8 Chain block design for 10 patients and 10 raters Page 22

$\begin{array}{lll}\text { Table } 9 & \text { Descriptive statistics of patients - Part A } & \text { Page } 29\end{array}$

$\begin{array}{lll}\text { Table } 10 & \text { Agreement coefficients } & \text { Page } 30\end{array}$

Table $11 \quad$ Strength of agreement of 15 tested movements $\quad$ Page 31

Table 12 Descriptive statistics of patients - Part B Page 32

Table 13. Descriptive statistics of raters - Part B Page 33

Table 14. Analysis of variance of total scores Page 33

Table 15. Principal component factor analysis of the correlation Page 37 Matrix for AMS scores

Table 16. Root contribution to motion tested Page 39 


\section{LIST OF FIGURES}

Figure $1 \quad$ The brachial plexus

Page 3

Figure $2 \quad$ Mallet scale

Page 10

Figure 3 Brachial plexus evaluation - Physiotherapy Department, Page 17 The Hospital tor Sick Children

Figure $4 \quad$ Normal probability plot of residuals trom analysis of Page 34 variance

Figure 5 Box plot comparison of AMS score distribution by patient Page 35 and rater factors - Part $B$

Figure 6 Box plot comparison of AMS score distribution by rater Page 36 Experience - Part B

$\begin{array}{lll}\text { Figure } 7 & \text { Scree plot of correlation matrix } & \text { Page } 38\end{array}$ 


\section{LIST OF APPENDICES}

Appendix I Guidelines For Use Of The Active Movement Scale

Page 61

Appendix 2 AMS Evaluation Form

Page 63

Appendix 3 Consent Form For Patient Participants - Part B

Page 6t

Appendix 4 Patient Participant Questionnaire - Part B

Page 68

Appendix 5 Consent Form For Health Care Professionals - Part B

Page 69

Appendix 6 Rater Questionnaire - Part B

Page 73 


\section{LIST OF ABBREVIATIONS}

OBPP

AMS

MRC

HSC

IQR

ICC
Obstetrical brachial plexus palsy

Active Movement Scale

British Medical Research Council

The Hospital tor Sick Children

Interquartile range

Intraclass correlation 


\section{INTRODUCTION}

The evaluation of upper extremity motor power in infants with obstetrical brachial plexus palsy (OBPP) presents a significant challenge to clinicians involved in their care. The ability to accurately document motor tunction and to measure change (or lack of change) in movement over time has important implications for determining the natural history of OBPP, deciding on appropriate treatment options and measuring treatment outcomes. Although a number of evaluative tools have been used to quantify upper extremity motor power and function in infants with upper extremity weakness, there are no reports to date of the reliability or validity of these tools. The Active Movement Scale (AMS) is a measurement system that has been co-developed by the candidate in the Brachial Plexus Clinic at The Hospital for Sick Children for the evaluation of infants with OBPP. It is expected that this new tool will enable clinicians to perform more reliable evaluations of these infants than with measurement systems that are currently available.

\section{HYPOTHESIS}

The Active Movement Scale is a reliable tool for the evaluation of upper extremity movement in infants with obstetrical brachial plexus palsy.

\section{OBJECTIVES}

\section{Overall Objective:}

The overall purpose of this research is to determine if the Active Movement Scale is a reliable tool for the evaluation of upper extremity movement in infants with obstetrical brachial plexus palsy. 
Specific Objectives:

The reliability of the Active Movement Scale was be determined by conducting two complementary studies. The specific objectives were:

1. To determine the inter-rater reliability of the Active Movement Scale when two experienced physiotherapists use the scale to evaluate infants with obstetrical brachial plexus palsy. (Part A)

2. To examine the dispersion of Active Movement Scale scores of infants with obstetrical brachial plexus palsy when evaluated by trained physiotherapists. (Part B)

\section{LITERATURE REVIEW}

\section{THE BRACHIAL PLEXUS}

\section{tnatomy}

The brachial plexus is a network of nerves that extends from the neck into the axilla and supplies the motor. sensory and sympathetic nerve tibres to the upper limb. Although numerous variations in the formation of the plexus have been reported, the following arrangement according to Leffert ${ }^{l}$ can be taken as a point of reference. The anterior primary ramus of $\mathrm{C} 5$ joins that of $\mathrm{C} 6$ to form the upper trunk, while $\mathrm{C} 8$ joins $\mathrm{T} 1$ in a similar fashion to form the lower trunk. $\mathrm{C} 7$ continues between the two to constitute the intermediate or middle trunk. Each of these trunks then splits into an anterior and a posterior division. The anterior division of the upper and middle trunks unite to form the lateral cord, which gives off the lateral root of the median nerve and the musculocutaneous 
nerve. The anterior division of the lower trunk forms the medial cord, which gives rise to the medial root of the median nerve and the ulnar nerve. The posterior division of the three trunks unite to form the posterior cord which provides the radial, axillary and subscapular nerves. It is through this nerve complex that all motor and sensory communicultion of the upper extremity is conducted to and from the spinai cord and brain.

Figure 1 is a schematic representation of the brachial plexus. ${ }^{2}$

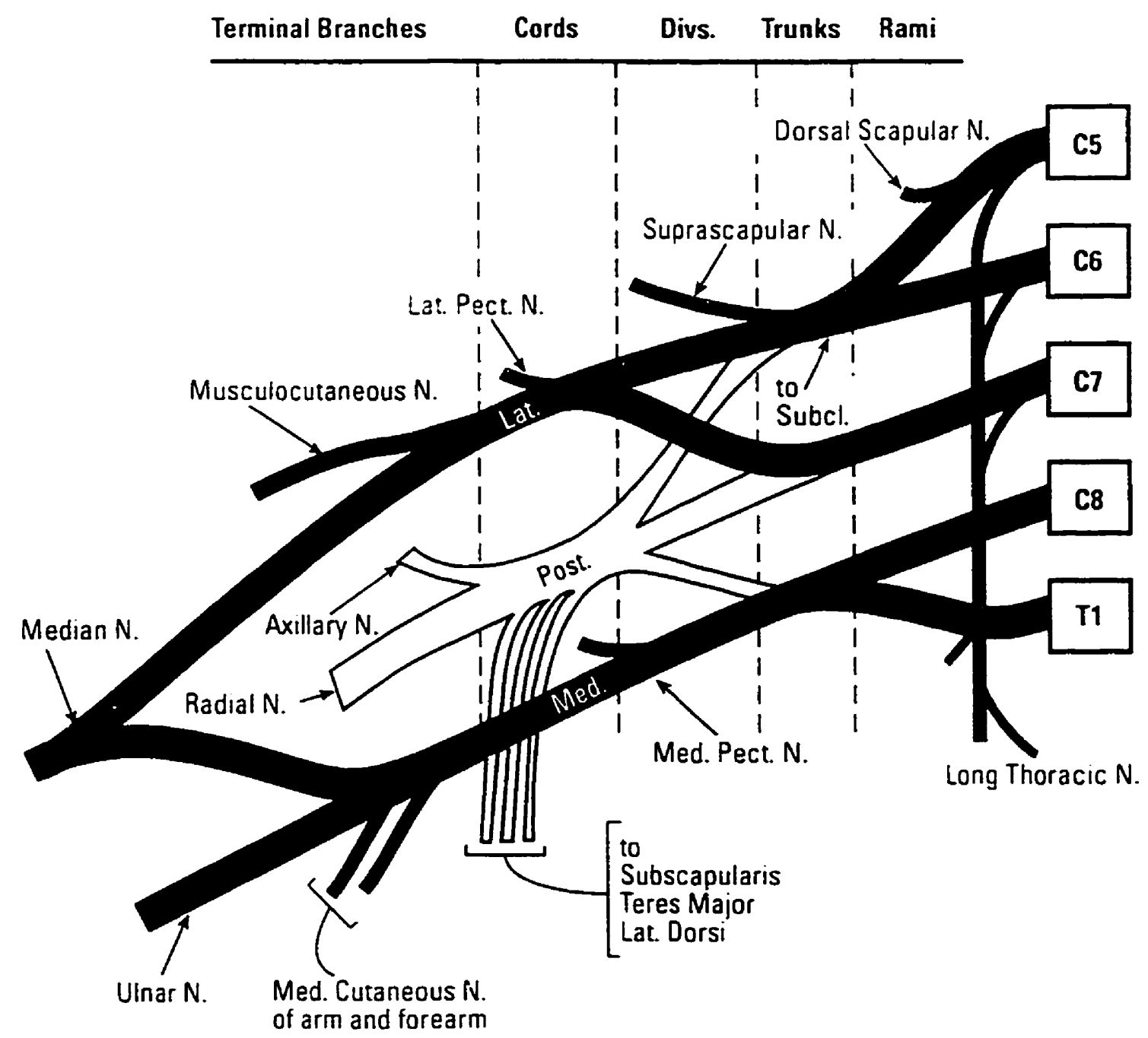

Figure 1. The brachial plexus

Adapted with permission from Clinically Oriented Anatomy (second edition), K.L. Moore (ed.), 1985, p 650 . 
OBSTETRICAL BRACHIAL PLEXUS PALSY

\section{Historical Background}

The tirst report of upper extremity paralysis in an infant following delivery was by Smellie $^{3}$ in 1768 who believed the condition was due to prolonged pressure on the arm while the child was in the pelvis, however it was Duchennet in 1872 who brought medical prominence to the condition by attributing it to birth trauma. He recognized that the lesion might occur in obstetric operations such as disengaging the upraised arm in a breech or footling presentation, in delivering after version or in making traction on the arm of the child after birth of the head. Erb ${ }^{5}$ described a similar pattern of paralysis in adults in 1874, since which time isolated upper extremity paralysis has commonly been known as "Erb-Duchenne " or simply " Erb's palsy." Klumpke 6 was the first physician to describe and elucidate the mechanisms of lower brachial plexus palsy in adults in 1885 and the term "Klumpke's palsy" is used today to characterize paralysis in the motor distribution of the lower plexus.

\section{Etiology of OBPP Injuries}

Brachial plexus injuries in newborns occur as a consequence of difficult childbirth 4,7

although the occasional report exists to the contrary. 8 The mechanism of injury depends upon whether the birth is breech or vertex. Sever ${ }^{7}$ described how damage to the upper nerves of the brachial plexus occurs during vertex delivery when shoulder dystocia 
necessitates excessive lateral flexion of the neck to free the shoulder from the pubic arch. This procedure causes direct traction on the roots of the plexus and when force is used probably cause injuries to the nerves.

Brachial plexus injury during breech delivery generally arises in lower birth-weight infants $^{9}$ and is assumed to happen as the head is tinally extracted. Damage to lower roots can be precipitated by hyperextension of the arm in a breech delivery, but most often it is the result of hyperextension of the head 10 during a face presentation producing a total plexus injury. Bilateral plexus involvement is more common following breech birth. 11

Other factors associated with obstetrical brachial plexus palsy are fetal macrosomia, maternal diabetes and forceps or vacuum extraction. 12,13

Metaizeau et al. ${ }^{14}$ studied brachial plexus lesions in a series of stillborn infants by producing traction on the head when the shoulder was restrained. They found that rupture was much more common in the upper roots and avulsion in the lower. Avulsion injuries occurred at the junction of the rootlets and the spinal cord.

\section{Incidence}

The incidence of obstetrical brachial plexus palsy in the United States has been reported from $0.5-2.6$ per 1000 live, full-term births. $12,13,15,16$ The only Canadian 
figures on the incidence of Erb's Palsy is from the province of Saskatchewan in which an incidence of 0.615 cases per thousand live births were reported in a 9-year period (1984 1993). 17

The right arm is involved in infants more frequently than the left due to the more common left occiput anterior position of the descending fetus. ${ }^{10}$ The incidence of obstetrical brachial plexus injuries in male and female in fants is roughly equal. 18-20

\section{Classification}

Intants with Erb's palsy or upper root lesions. display weakness or paralysis of the muscles served by $C 5, C 6=C$ ? . The classic position of the affected arm, resulting from involvement of the upper roots is adduction and internal rotation of the shoulder. extension of the elbow. pronation of the forearm and flexion of the wrist. This posture may also occur in the absence of elbow extension because gravity holds the arm at the side of the supine infant. 21

Patients with total brachial plexus palsy $(\mathrm{C} 5, \mathrm{C} 6, \mathrm{C} 7, \mathrm{C} 8=\mathrm{T} 1)$ are more severely affected and have involvement of hand grasp function. 22 Total palsy is characterized by complete atonia of the extremity. 23 The fingers may rest in a flexed posture - a result of the tenodesis effect at the wrist rather than true power in the long flexors of the digits. Sensation may be absent although this is extremely difficult to test in infants. 21 


\section{Natural History}

The degree of spontaneous motor recovery in children with OBPP varies widely. Some studies suggest that the majority of infants recover sufficiently and do not require primary surgical intervention. 19,20,24 Although many infants with brachial plexus lesions recover with minor or no tunctional deficits, a number of children will develop functional limitations as a result of bony deformities and joint contractures.22 Advances in microsurgical techniques and paediatric anaesthesia have led to a renewed interest in the surgical management of this condition. $11,18,25-32$ The lack of a uniform grading system however, makes it difficult to compare outcome studies and to determine the natural history and hence the prognosis of brachial plexus lesions in infants. 33.34

\section{ASSESSMENT OF MOTOR FUNCTION}

\section{British Medical Research Council Scale}

A number of methods have been used to describe or quantify motor function in children with OBPP. The British Medical Research Council (MRC) ${ }^{35}$ system of manual muscle testing is the most recognized scale for the evaluation of strength for patients with peripheral nerve injuries (Table 1). This test employs the use of limb segment positioning without and against gravity and the use of manual resistance to grade muscle strength on a 6-point scale $(0=$ no contraction, $5=$ normal power $)$. The MRC scale as a measure of strength for infants with OBPP has been reported by a number of authors. $19,25,30,31,36$ - 
Table 1. British Medical Research Council System of manual muscle testing

\section{Observation}

No contraction

Flicker or trace of contraction

Active movement with gravity eliminated

Active movement against gravity

Active movement against gravity and resistance

Normal power

\section{Muscle Grade}

0

1

2

3

4

5

Data trom Aids to the Investigation of Peripheral Nerve Injuries. ed 2. (Medical Rescarch Council War Memorandum, vol 7.) London. His Majesty's Stationary Office. 1943. p +8.

Gilbert and Tassin Scale

Gilbert and Tassin ${ }^{40}$ have suggested a modified MRC scale for the evaluation of children with OBPP to account tor the difficulties encountered in examining infants with manual resistance (Table 2). The M0-M3 scale has been used as an outcome measure in some studies. $9.27 .37 .+1$ This scale is limited in the ability to distinguish improvements in motor recovery however, as it has only one grade to classify partial movement. 
Table 2. Gilbert and Tassin system of muscle grading

\section{Observation}

No contraction

Contraction without movement

Slight or complete movement with weight eliminated

Complete movement against the weight of the corresponding segment of extremity

\section{Muscle Grade}

$\mathrm{M} 0$

Ml

$\mathrm{M} 2$

$\mathrm{Ml} 3$

Data from Gilbert A. Tassin. J-L. Obstetrical plasy: A clinical, patholugic and surgical review. In Terzis JK. Editor. Microreconstruction of Nerve Injunes. Philadelphia: WB Saunders: 1987. P.532.

\section{Wallet Scale}

Mallet ${ }^{+2}$ has described a method of evaluating children with OBPP based on the ability to perform functional positioning of the affected limb (Figure 2). Although

utilized as an outcome measure by a number of authors, $18,32,43-46$ this system can only be used with a cooperative, older child. This scale is not suitable for use with infants and it cannot be used as both a pre-operative and post-operative evaluative tool as accurate grading requires that the subject carry out the examiners instructions. 


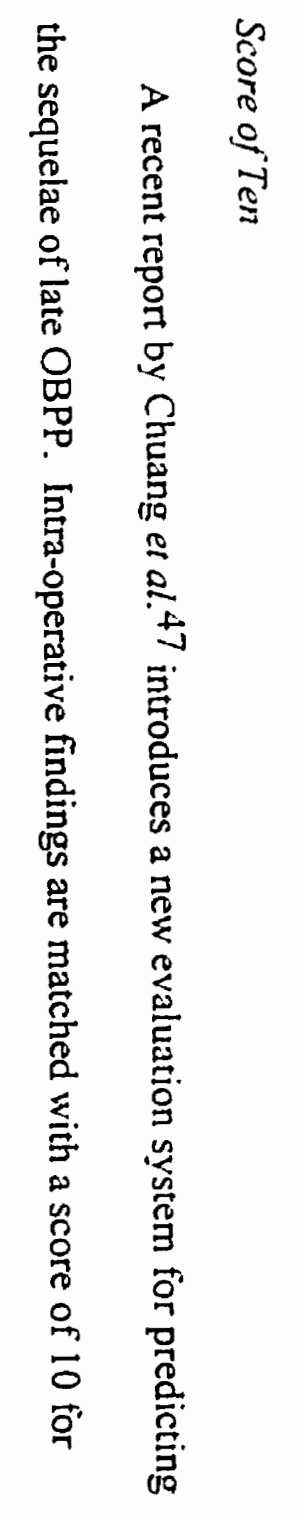

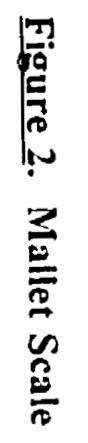

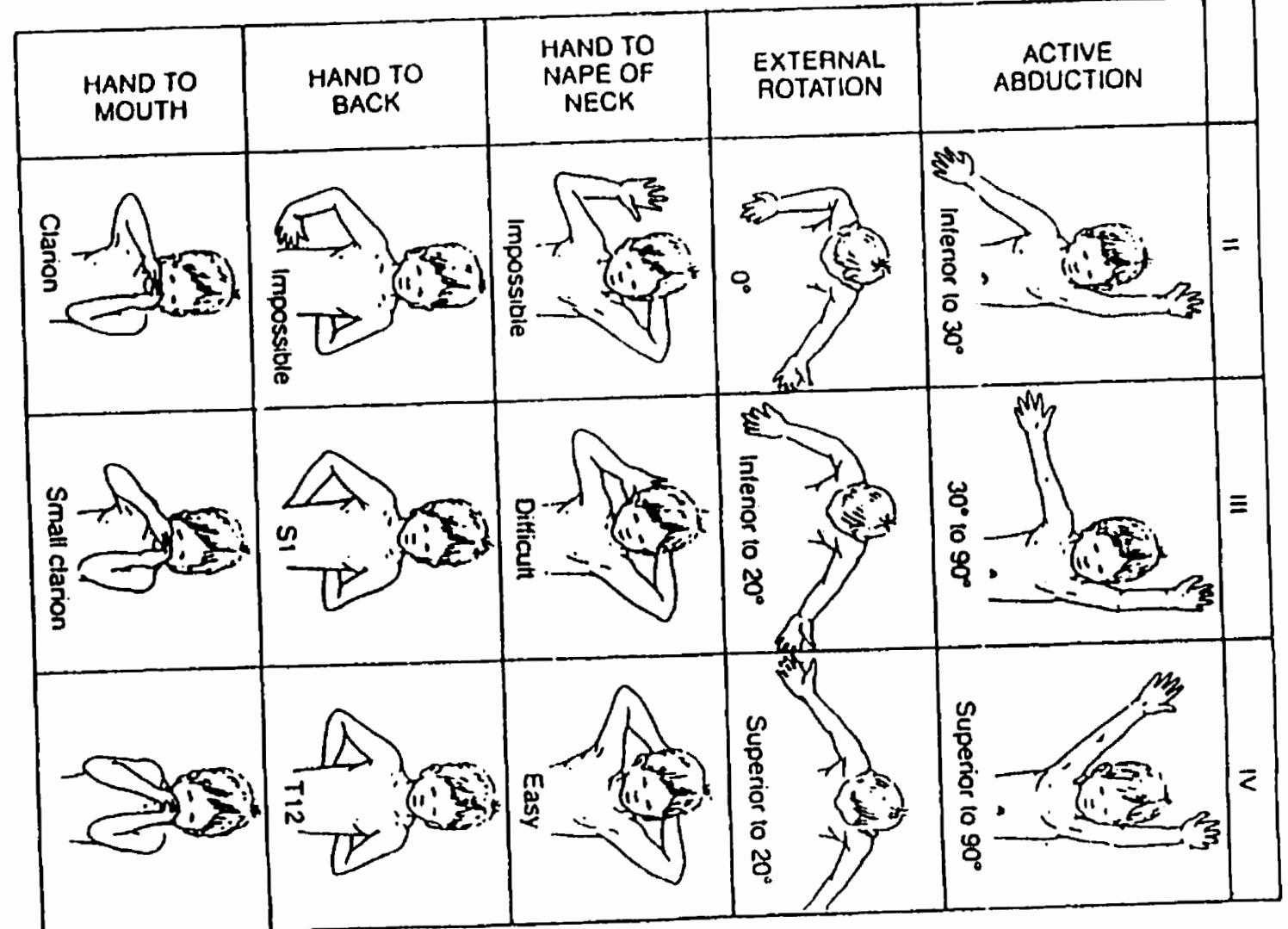


predicting late functional results (Table 3). The "Score of 10 " is calculated by combining Erb and Klumpke scores. The Erb score gives points for upper plexus tunctions including shoulder abduction, shoulder external rotation, elbow flexion, elbow extension. forearm supination, forearm pronation and trumper sign. The Klumpke score awards points for lower plexus functions including wrist extension, wrist flexion. metacarpophalangeal joint extension. interphalangeal joint extension. tinger flexion. thumb abduction and thumb adduction.

Table 3. Score of 10 relationship between early and late obstetric brachial plexus palsy

Type Intraoperative Findings

(Early)

1 Individual neuroma of $\mathrm{C} 5-\mathrm{C} 7$

$2 \quad$ Mixed complex neuroma of upper trunk and/or middle trunk with less scars

3 Mixed complex neuroma of upper trunk and/or middle trunk with dense scars

$+\quad$ C5, C6, or C5-C7 root avulsion
Predictable Sequelae (Late)

Good Erb scores

Acceptable Erb scores

Erb scores

Poor Erb scores 


\section{Impairment Scales}

In a retrospective study, Eng et al. 34 used two impairment-rating scales to correlate functional outcome with conservative management. One scale was used to classify newbom function on initial examination (Table 4) and a second scale was used to evaluate late outcome (Table 5). They tound on comparison of initial and final clinical findings that there was high agreement (correlation $r=0.81, p<0.001$ ) between the two impairment scales. These scales have not appeared elsewhere in scientitic literature. 
Table 4. Impairment rating scale for OBPP patients on initial physical exam.

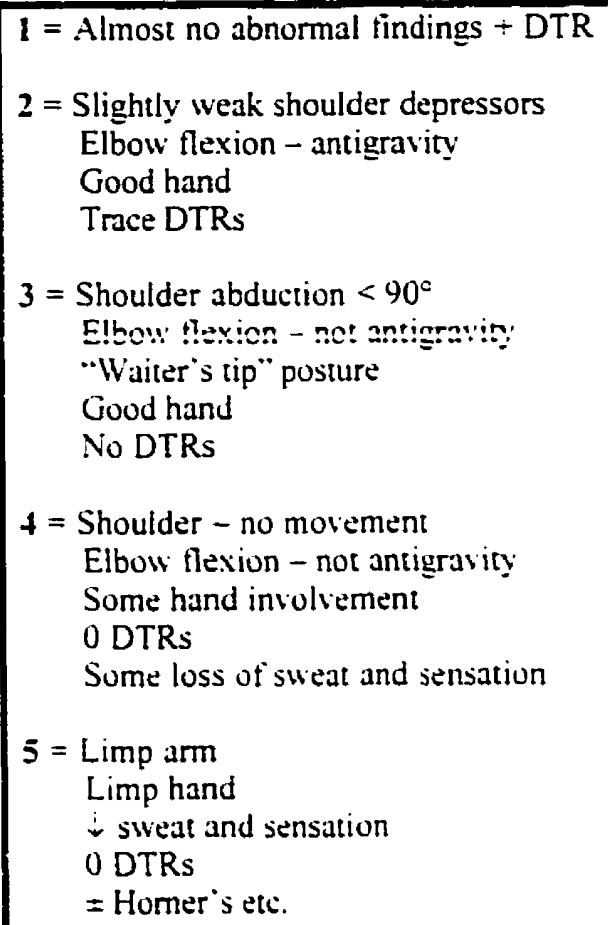

Table 5. Impairment rating for brachial plexus palsy on follow up.
1. Mild
Minimal winging of scapula
Abducts to $90^{\circ}$ or more
Some external rotation
Good biceps (antigravity $\rightarrow$ )
Minimal loss of supination
Normal sweat and sensation
Good hand use

\section{Hoderate}
Obvious scapula winging
Shoulder abduction less than $90^{\circ}$ with substitution of trapezius and serratus anterior in shoulder elevation
Uses short head of biceps with deltoid to lift arm
Flexion contracture of elbow
Antigravity biceps
Good wrist and finger extensors and flexors
Good hand
3. Moderate to severe
Marked scapular winging
Shoulder abduction $<45^{\circ}$
Elbow contracture
No supination of the forearm
Biceps not antigravity in strength
Poor hand function
Some loss of sweat and sensation

\section{Severe}
Marked scapular winging
Shoulder abduction $<45^{\circ}$
Elbow contracture, no supination
Biceps movement negligible
Loss of hand function
Severe loss of sweat and sensation
Withered arm or agnosia of the arm

Adapted from Eng GD. Binder $\mathrm{H}$, Getson $\mathrm{P}$ et al.. Obstetrical brachial plexus palsy (OBPP) outcome with conservative management. Muscle \& Nerve, 19:88+-91; 1996: permission pending. 
Descriptive Measures

A number of scientific reports use descriptive accounts of function such as; "good", "fair" or "poor" to characterize clinical and surgical outcomes. $10,18,48-51$ Comparison of results between these studies is impossible and evaluation of the individual studies themselves is problematic. This is due to the varied or limited descriptions of movement and function that these items represent and to the lack of standardization and validation of these descriptors.

The Active Lovement Scale

The Active Movement Scale (Table 6) is an eight-grade. ordinal scale that was codeveloped by the candidate and the head of the Brachial Plexus Clinic at The Hospital for Sick Children (HSC) for the specific purpose of evaluating infants (newborn to one year of age) with obstetrical brachial plexus palsy. 2l This tool is used to quantify upper extremity strength by observing spontaneous, active movement both without and against gravity. Guidelines have been developed for the use and application of this tool and are found in Appendix 1. The use of this scale for clinical and scientific evaluation has been reported in a number of publications. $26,28,52,53$ 
Table 6. Active Movement Scale

\begin{tabular}{|lc|}
\hline \multicolumn{1}{|c|}{ Observation } & Muscle Grade \\
Gravity eliminated & \\
No contraction & 0 \\
Contraction, no motion & 1 \\
Motion $\leq 1$, range & 2 \\
Motion $>1 / 2$ range & 3 \\
Full motion & + \\
Against gravity & \\
Motion $\leq 1,2$ range & 5 \\
Motion $>1,2$ range & 6 \\
Full motion & 7 \\
\hline
\end{tabular}

\section{Development Of The Active Movement Scale}

Prior to the inception of the HSC Brachial Plexus Clinic, physiotherapists at the institution used a measurement system described by Shepherd ${ }^{54}$ for the evaluation of infants with OBPP. She suggested that motor function should be analyzed by observing:

1) spontaneous movement and posture as the infant lies in the supine and prone positions and is moved around, cuddled and talked to

2) motor behavior during testing of reflexes and reactions, particularly of the Moro reflex, the placing reaction of the hands, the Galant (trunk incurvation) reflex. the neck righting reaction and the parachute reaction 
Muscle activity was graded and recorded using the following simple system:

$$
\begin{aligned}
& 0=\text { Absent } \\
& 1=\text { Present, but lacking full range of movement } \\
& 2=\text { Present throughout a full range of movement }
\end{aligned}
$$

A tlow sheet was developed in the Physiotherapy Department at HSC on the basis of this system (Figure 3 ) in which movements for individual muscles of the upper extremity were recorded and graded over subsequent examinations. It became apparent however that individual muscles as outlined on this form were impossible to evaluate. assessments were lengthy to perform and the three grades gave little intormation as to the change in movement over time.

The evolution of the HSC Brachial Plexus Clinic necessitated the development of an evaluative tool that was simple and rapid to use. appropriate for infants and young children, amenable to statistical analysis and standardized. The AMS was developed and adopted into practice by the clinic in 1991. Active range of motion of fifteen movements of the upper extremity are evaluated using the AMS (Appendix 2). These movements were chosen for the following reasons: they provide representation for all 5 nerve roots, they highlight function of the entire upper extremity and they are relatively easy to assess. 


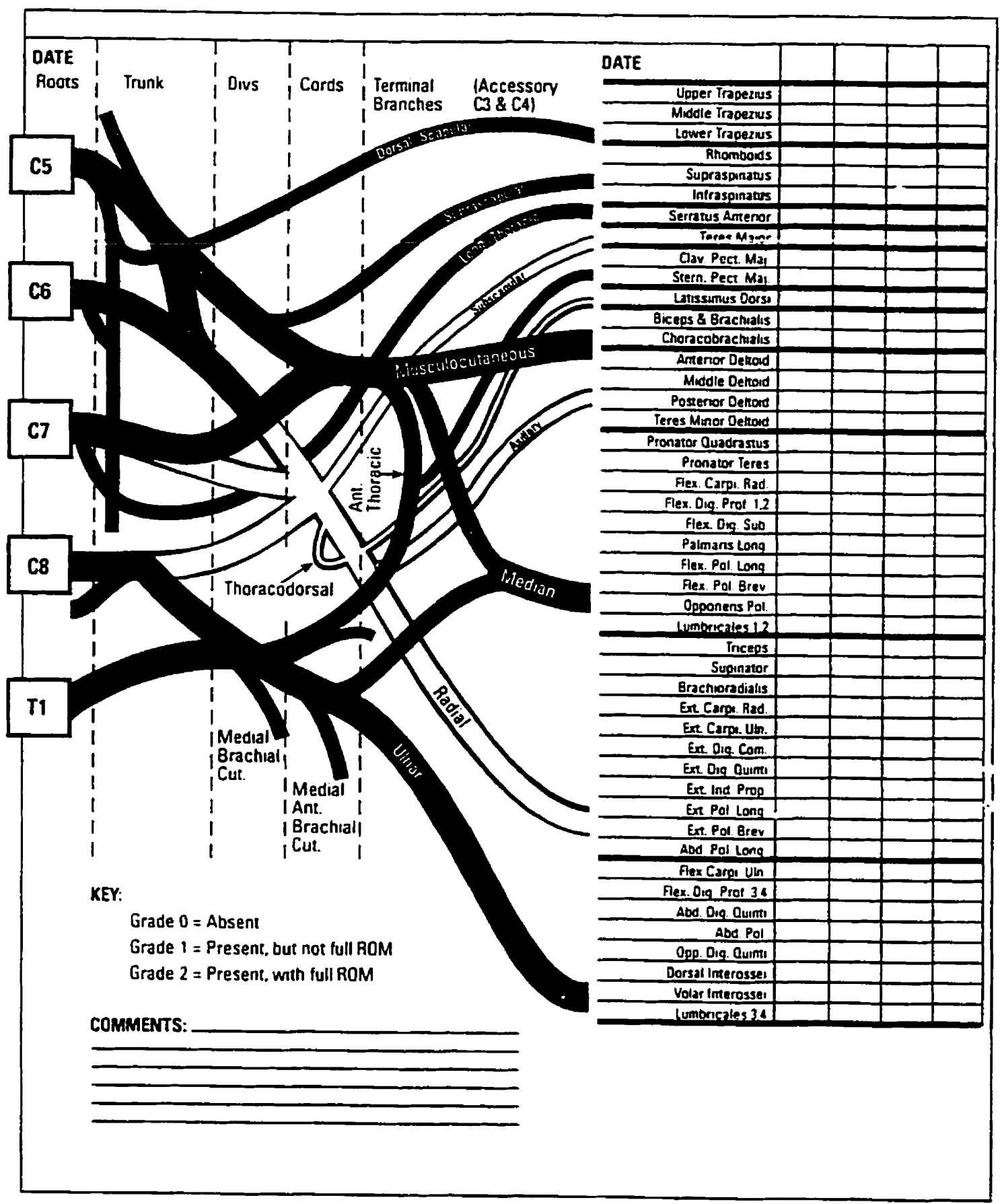

Figure 3. Brachial plexus evaluation - Physiotherapy department, Hospital for Sick Children 


\section{SCOPE OF THE PROBLEM}

Obstetrical brachial plexus palsy is a form of birth trauma that affects one or more of the five nerve roots of the brachial plexus. Lesions to these nerve roots occur in approximately one per thousand live births. The condition is characterized by varying degrees of motor paralysis and sensory loss in the involved upper extremity. The natural history of this form of trauma ranges from complete recovery to significant motor and functional impairment. Microsurgical reconstruction is an option for some infants. Without a standardized measure of outcome. however, the effectiveness of this intervention and the natural history OBPP is uncertain.

The lack of a reliable grading system prohibits the accurate evaluation of other therapeutic interventions such as muscle strengthening as facilitated by Physiotherapists and splinting as provided by Occupational Therapists. A review of the literature reveals that no evaluative tool has been reported that is reliable for quantifying motor function in infants with upper extremity paralysis.

\section{MATERIALS AND METHODS}

\section{INTER-RATER RELIABILITY STUDY - PART A}

\section{Study Design}

A single trial design using multiple patients was used to determine total reliability and chance agreement of the AMS by two experienced raters. Consecutive rather than 
simultaneous evaluation of the patients was conducted due to the necessary interaction between rater and infant that is required to properly apply the tool.

The sample size requirement for this study was estimated according to the

recommendations of Donner and Eliasziw. 55 With a type-l error $=0.05$ and power $=$ 0.80 . it was calculated that a minimum of 50 patients were required to demonstrate an underlying true reliability of the AMS.

\section{Patients}

Sixty-three infants under the age of one vear with a unilateral brachial plexus lesion as determined by the Brachial Plexus Team at The Hospital for Sick Children were selected as a sample over a 28 month period. Children with a concomitant diagnosis such as neurological conditions (birth asphyxia. cerebral palsy) or tracture (clavicle, humerus, rib) were excluded as potential subjects. The families were informed about the study by the clinic physiotherapist (primary investigator) in consecutive order as they presented in the Brachial Plexus Clinic. and verbal consent to participate in the data collection was obtained from a parent of each child.

\section{Raters}

Two pediatric physical therapists from the Hospital for Sick Children, each experienced in using the AMS (greater than 20 assessments each prior to starting the study), performed evaluations on the same 63 infants using the scale. One of the two evaluations was performed by the Brachial Plexus Clinic physiotherapist (Masters 
candidate and primary investigator) as part of the routine clinic assessment. The raters evaluated 15 functional movements of the affected arm of each child using the same standardized form that is used in the HSC Brachial Plexus Clinic (Appendix 2). Raters were randomly assigned to be first assessor by coin toss and were blinded to the other rater's tindings. The evaluations by each rater took no longer than 15 minutes to complete. Consistency within the study was facilitated through the use of the operational instructions for the application of the AMS (Appendix 1).

Statistical tnalysis - Part tt

The three tests of agreement that were used to analyze the data from Part $A$ of the study were percentage agreement. kappa and quadratic-weighted kappa. Percentage agreement is a reliability test for categorical variables. estimating the ability of researchers to agree on category ratings. ${ }^{56}$ In this study, it was a measure of how often the raters agreed on the score for each of the 15 tested movements.

Kappa is an appropriate measure of ordinal data that calculates the average rate of agreement and controls for expected agreement by chance. ${ }^{57}$ It has a maximum of 1.00 when agreement is perfect and a value of 0 indicates no agreement better than chance. Landis and Koch ${ }^{58}$ have categorized the kappa statistic according to strength of agreement and these divisions are represented in Table 7. 


\section{Table 7. Agreement Measures For Categorical Data}

\section{Kappa Statistic}

$$
\begin{gathered}
<0.00 \\
0.00-0.20 \\
0.21-0.40 \\
0.41-0.60 \\
0.61-0.80 \\
0.81-1.00
\end{gathered}
$$

\author{
Strength of Agreement \\ Poor \\ Slight \\ Fair \\ Moderate \\ Substantial \\ Almost Perfect
}

Adapted from Landis, JR, Koch GG. The Measurement of Observer Agreement tor Categorical Data. Biometrics 1977;33:150-174: permission pending.

Weighted kappa ${ }^{59}$ coefficients were also used to determine if disagreement between the rater's scores was minor (differing by only one or two grades) or extreme. For this study we chose quadratic weights, which base disagreement weights on the square of the amount of discrepancy. 60

\section{VARIABILITY STUDY - PART B}

\section{Study Design}

A chain-block study design, using 10 patients and 10 raters was selected to examine the variability of AMS scores. (Table 8) This design was utilized for two purposes. First, to facilitate the randomization of raters and patients. Second, to provide a practical means of obtaining a total of 30 assessments in a single test period. 
Table 8. Chain block design for 10 patients and 10 raters

\begin{tabular}{|cccc|}
\hline Rater & \multicolumn{3}{c|}{ Patient } \\
I & A & B & A \\
2 & B & C & B \\
3 & C & D & C \\
4 & D & E & D \\
5 & E & F & E \\
6 & F & G & F \\
7 & G & H & G \\
8 & H & I & H \\
9 & I & J & I \\
10 & J & A & J \\
\hline
\end{tabular}

The advantages of this design were: the data could be collected in a single day of testing. 30 assessments could be obtained from 10 patients and only a brief interval separated the assessments.

\section{Patients}

The patient sample was obtained from the database of the Brachial Plexus Clinic at HSC after approval for the study was obtained from the institutions' Research Ethics Board. A list of potential patients was generated from the database according to the following criteria:

1) under one year of age as of November 13,1999

2) diagnosis of a unilateral obstetrical brachial plexus palsy made by the HSC Brachial Plexus Clinic 
3) no previous fractures (clavicle, humerus, ribs)

4) no central nervous system involvement (e.g. cerebral palsy)

5) living within a 2 hour drive of HSC

Forty-seven patients met the above listed inclusion criteria. Using a table of random numbers 61 the 47 potential subjects were randomized and then listed in ascending, numerical order. From this list. the families were contacted in ascending. numerical order by the Brachial Plexus Clinic physiotherapist (primary investigator of the project). The study was thoroughly explained to the parent(s) of each child and if there was agreement to participate, they were asked to sign a consent form (Appendix 3 ) and a demographic questionnaire. (Appendix + ) Two additional infants were recruited as back-up subjects for the day of evaluation. Families of the patients were offered a $\$ 40$ stipend to offset the costs of transportation and parking.

\section{Raters}

Volunteer raters were sought from the Physiotherapy Departments at the Hospital for Sick Children and the Bloorview McMillan Children's Treatment Centre. Signs were posted in each of the departments that explained the study and called for licensed physical therapists, currently employed with 2 or more years of full time pædiatric experience who were interested in participating in the study. A stipend of $\$ 40$ was offered to the volunteers to offset the cost of transportation and additional costs that would be incurred by participating in the teaching workshop and data collection. The first 10 respondents 
who met the inclusion criteria and signed a consent form (Appendix 5 ) were selected for the study. Each rater was also asked to complete a demographic questionnaire. (Appendix 6) AMS Teaching Workshop

A l-hour workshop to teach the raters about the Active Movement Scale and to standardize its application for infants with obstetrical brachial plexus injuries was conducted on the evening prior to the data collection. The primary investigator of this study (co-developer of AMS and HSC Brachial Plexus Clinic Physiotherapist) organized and led the teaching session. The workshop was held in the main auditorium at HSC. This venue was able to accommodate multimedia presentations that included overhead projection, slide presentation and large-screen video viewing. In addition. an open floor space at the front of the auditorium was suitable for a patient demonstration by the tacilitator and practice with dolls by all the raters.

The initial 15 minutes of the workshop was dedicated to a didactic review of obstetrical brachial plexus palsy; the anatomy of the brachial plexus, etiology of obstetrical plexus injuries, the nature of brachial plexus lesions and the natural history of OBPP. Three, large, teaching diagrams from the Brachial Plexus Clinic were used to illustrate these points. Questions from the raters were encouraged through the lecture and throughout the entire workshop.

The second 15 minutes of the workshop was scheduled to introduce the Active Movement Scale and discuss its application for in fants with OBPP. An oversized poster 
of the scale was used as a visual aid by the facilitator and three additional posters were located around the floor area to be used as reference for the raters during the practice sessions. Each rater had a handout package that included; 3 sample data collection sheets, each with a copy of the scale (Appendix 2), detailed guidelines for use of the scale (Appendix l) and a time, room and assistant schedule for the following days evaluations.

A 15-minute video was then shown to the raters that reviewed the AMS and demonstrated the evaluation of 3 infants with OBPP by the clinic physiotherapist. The video highlighted 3 intants of varying ages and severity of peripheral nerve involvement a newborn with a total brachial plexus palsy, a 6 month old who was two months post surgery for brachial plexus reconstruction and a one year old with mild upper root involvement. Discussion following the video emphasized cues and techniques for encouraging active movement in infants and children.

The fourth section of the workshop was a live demonstration of the evaluation of a child with brachial plexus palsy by the facilitator. The patient was a 12 month-old girl that was 3 months post brachial plexus reconstruction. The child was a patient followed through the Brachial Plexus Clinic at HSC. The parent of the child was approached to participate in the demonstration during a regular physiotherapy two weeks prior to the workshop. A full description of the assessment was described to the parent and verbal consent to participate was given. During the workshop the therapist demonstrated the 
techniques for performing an evaluation on a child using the AMS. This demonstration lasted 15 minutes.

The final half-hour of the session was directed at allowing the raters to have an opportunity to practice performing AMS evaluations on dolls. The raters paired off in 5 groups of 2 and positioned themselves on the floor in view of an AMS poster. The pairs of raters each shared a life-sized. infant doli $(66 \mathrm{~cm}$ in length) that had flexible shoulders, elbows and wrists. The facilitator described a limb position that the raters then reproduced on their doll. The raters were then asked to grade the movement according to the guidelines for use of the AMS and record the grade on one of the data collection sheets. In this tashion. 15 movements were graded and recorded on a data sheet. The scores for the movements were compared amongst the raters and discussion was held when there was discrepancy between scores. This process was repeated 2 more times using different movement scenarios. Each rater had an opportunity to independently complete an evaluation as their partner positioned the dolls' limb.

Although formal evaluation of rater competency following the AMS teaching workshop was not the intent of this study, it was felt that a sense of rater confidence at the conclusion of the teaching session would be useful. Immediately following the workshop, the raters were asked by show of raised hands if they felt confident that they could use the AMS scale to assess upper extremity movement in infants with obstetrical 
brachial plexus palsy. All raters confirmed that they felt confident in this matter by raising their hands.

\section{Data Collection}

All data for Part B of the study was collected on the day following the teaching workshop. Each child received a total of 3 assessments by 2 raters. A washout effect between evaluations was tacilitated by separating the intra-rater assessments (first and third for each rater) with the evaluation of a second child.

The assessment involved the evaluation of 15 joint movements of the involved upper extremity using the Active Movement Scale (Appendix 2). The raters performed the evaluations in accordance with the guidelines outlined in Appendix 1. The evaluations were conducted in one of four separate rooms. Each room contained a soft mat on the floor covered by a clean sheet. Multiple, age-appropriate toys and rattles were available for the use of the raters. Each room contained a poster version of the AMS that could be easily viewed by the rater during the evaluation. An enlarged example of the data collection sheet was posted in proximity to each rater. As a rater completed evaluating one of the 15 movements, she verbally conveyed her score to an assistant who then recorded the number on hidden data sheet and checked off the appropriate movement as being completed on the posted example sheet. In this manner, all 15 movements were evaluated by each rater. 
Evaluations were scheduled a maximum of one half-hour apart with each assessment taking no longer than 15 minutes to complete. Raters were blinded to the results of their previous assessments and to the assessments of the other raters.

\section{Statistical Analvisis - Part B}

A general linear, two-way analysis of variance was used to test the significance of variance in scores due to rater and patient factors. Box plots displaying the $25^{\text {th }}$ and $75^{\text {th }}$ centiles. inter-quartile range and median were constructed to compare the variability of factors between and within raters and patients. The interquartile range (IQR) is a measure of data dispersion. A large amount of dispersion of the IQR indicates significant variability of the data. 62 A coefficient of 100 on the $y$-axis of the box plot indicates perfect assessment of health.

Post hoc principal component factor analysis of the data was conducted to determine if there was a score-based effect underlying the instrument. This exploratory approach was used to examine the structure within the variables, in an attempt to provide insight as to the nature of their interrelationships. A correlation matrix of the scores was developed using a varimax rotation, to convert the AMS measures to standard scores. A scree plot was constructed from this matrix using the eigenvalue test 60 to determine the number of factors that were underlying the 15 items of the scale. 


\section{RESULTS}

INTER-RATER STUDY - PART A

The descriptive statistics for patients in Part A of the study are listed in Table 9. The male to female patient ratio was almost evenly divided and the ages within these groups were evenly distributed. Significantly more patients in the sample had right-sided involvement than left matching the OBPP population at large. ${ }^{10}$

Table 9. Descriptive statistics for patients - Part A

\begin{tabular}{|llccc|}
\hline Patients & $\begin{array}{c}\text { Mean age-mos. } \\
\text { [range] }\end{array}$ & Right side & Left side \\
male & $32(50.8 \%)$ & $5[1-11]$ & 18 & 14 \\
female & $31(49.2 \%)$ & $5[1-11]$ & 22 & 9 \\
total & 63 & $5[1-11]$ & $40(63.5 \%)$ & $23(36.5 \%)$ \\
\hline
\end{tabular}

Percentage agreement, kappa and quadratic-weighted kappa scores for the 15 tested movements are listed in Table 10. Forearm supination represented the least accurate percentage of agreement $(49 \%)$ between the two raters. Eight of the 15 movements were measured with total agreement $90 \%$ or more of the time. Analysis of the scores using the kappa statistic indicated a lower level of agreement for all 15 movements than was obtained using percent agreement alone. 
Table 10. Agreement coefficients - Part A

\begin{tabular}{|lcll|}
\hline Joint Movement & \% agreement & $\mathrm{K}(95 \% \mathrm{CI})$ & $\mathrm{K}_{\text {quad }}(95 \% \mathrm{CI})$ \\
\hline Shoulder Abduction & 51 & $0.37(0.23,0.51)$ & $0.72(0.64,0.80)$ \\
Shoulder Adduction & 92 & $0.64(0.39 .0 .89)$ & $0.75(0.51,0.97)$ \\
Shoulder Flexion & 63 & $0.54(0.39,0.68)$ & $0.82(0.74,0.89)$ \\
Shoulder External Rotation & 65 & $0.48(0.33 .0 .63)$ & $0.68(0.55,0.82)$ \\
Shoulder Internal Rotation & 95 & $0.55(0.10,1.00)$ & $0.62(0.17,1.00)$ \\
Elbow Flexion & 62 & $0.51(0.37,0.65)$ & $0.93(0.89,0.97)$ \\
Elbow Extension & 92 & $0.59(0.32,0.86)$ & $0.92(0.82,1.00)$ \\
Forearm Pronation & 97 & $0.49(0.00,1.00)$ & $0.49(0.00,1.00)$ \\
Forearm Supination & 49 & $0.33(0.19,0.46)$ & $0.56(0.41,0.71)$ \\
Wrist Flexion & 90 & $0.48(0.14 .0 .81)$ & $0.83(0.61,1.00)$ \\
Wrist Extension & 78 & $0.52(0.36,0.69)$ & $0.81(0.72,0.90)$ \\
Finger Flexion & 97 & $0.65(0.38,0.93)$ & $0.89(0.79,0.99)$ \\
Finger Extension & 98 & $0.88(0.64 .1 .00)$ & $0.98(0.94 .1 .00)$ \\
Thumb Flexion & 98 & $0.85(0.56,1.00)$ & $0.96(0.86,1.00)$ \\
Thumb Extension & 76 & $0.56(0.38,0.74)$ & $0.66(0.49,0.83)$ \\
\hline
\end{tabular}

With the effects of chance eliminated, the overall strength of agreement of the AMS

- was 0.51 with a $95 \%$ confidence interval of $0.46-0.56$ - a score considered in the moderate range of agreement (see Table 7). The overall quadratic weighted kappa coefficient of the AMS was 0.89 with a $95 \%$ confidence interval of 0.87 to 0.91 , indicating that the raters demonstrated excellent agreement using the scale as a whole and that any disagreements in scores that they had were small. Eight of the 15 movements, using quadratic weighted kappa, were in the highest strength of agreement category $\left(\mathrm{K}_{\text {quad }}\right.$ $=0.81-1.0)$. Five movements demonstrated substantial agreement $\left(\mathrm{K}_{\text {quad }}=0.6 \mathrm{I}-0.80\right)$ and two movements (pronation and supination) showed moderate agreement $\left(\mathrm{K}_{\mathrm{quad}}=0.4 \mathrm{l}-\right.$ 0.60) (Table II). 
Table 11: Strength of agreement of 15 tested movements - Part A

\begin{tabular}{|c|c|c|}
\hline $\begin{array}{l}\text { Moderate } \\
\left(\mathrm{K}_{\text {quad }}=0.41-0.60\right)\end{array}$ & $\begin{array}{l}\text { Substantial } \\
\left(\mathrm{K}_{\text {quad }}=0.61-0.80\right)\end{array}$ & $\begin{array}{l}\text { Excellent } \\
\left(\mathrm{K}_{\text {quad }}=0.81-1.0\right)\end{array}$ \\
\hline $\begin{array}{l}\text { pronation } \\
\text { supination }\end{array}$ & $\begin{array}{l}\text { shoulder abduction } \\
\text { shoulder adduction } \\
\text { shoulder external rotation } \\
\text { shoulder internal rotation } \\
\text { thumb extension }\end{array}$ & $\begin{array}{l}\text { shoulder flexion } \\
\text { elbow flexion } \\
\text { elbow extension } \\
\text { wrist flexion } \\
\text { wrist extension } \\
\text { finger flexion } \\
\text { finger extension } \\
\text { thumb tlexion }\end{array}$ \\
\hline
\end{tabular}

\section{VARIABILITY STUDY - PART B}

Descriptive statistics of the 10 patients and 10 raters in Part $B$ are tound in Tables 12 and 13 and were obtained from the data collected from questionnaires in Appendix 4 and Appendix 6. Review of the patient statistics suggests a highly varied sample. The male to female ratio was $6: 4$ and the ages were well distributed with a range of one month to one year. $90 \%$ of the patients had right-sided involvement. Three of the patients had total plexus involvement and two patients had undergone surgical brachial plexus reconstruction. 
Table 12. Descriptive statistics of patients - Part B

\begin{tabular}{|cccccc|}
\hline Patient & Gender & $\begin{array}{c}\text { Age } \\
\text { (mos.) }\end{array}$ & $\begin{array}{c}\text { Involved } \\
\text { Side }\end{array}$ & $\begin{array}{c}\text { Surgical Plexu: } \\
\text { Reconstruction }\end{array}$ & $\begin{array}{c}\text { Nerve Root } \\
\text { Lesion }\end{array}$ \\
\hline A & M & 0 & Right & No & Total \\
B & M & 1 & Right & No & Upper \\
C & M & 7 & Right & No & Total \\
D & M & 9 & Right & Yes & Total \\
E & F & i2 & Right & No & Upper \\
F & F & 3 & Right & No & Upper \\
G & M & 11 & Left & Yes & Upper \\
H & F & 8 & Right & No & Upper \\
I & M & 3 & Right & No & Upper \\
J & F & $1 !$ & Right & No & Upper \\
\hline
\end{tabular}

The raters in this study were all physical therapists with pediatric experience ranging from 2 to 30 years (mean of 12.5 years). Experience using the AMS ranged from none (6 raters) to over 50 patients (2 raters). 
Table 13. Descriptive statistics of raters - Part B

\begin{tabular}{|ccc|}
\hline Rater & $\begin{array}{l}\text { Years of Full-Time } \\
\text { Pediatric Employment }\end{array}$ & $\begin{array}{c}\text { Experience Using The Active } \\
\text { Movement Scale } \\
\text { (number of assessments) }\end{array}$ \\
\hline 1 & 30 & none \\
2 & 10 & over 50 \\
3 & 15 & $11-25$ \\
+ & 10 & nune \\
5 & 15 & none \\
6 & 6 & none \\
7 & 2 & none \\
8 & 12 & over 50 \\
9 & 11 & $1-5$ \\
10 & 14 & none \\
\hline
\end{tabular}

Table 14 presents the results for the general linear two-way analysis of variance of the rater's scores. With a $p$-ralue $<0.05$ and a high $F$ score, we rejected the hypothesis that there was no difference in scores due to rater and patient factors. The normal probability plot of the residuals found in Figure + indicates that the linear model is an adequate representation of the data.

Table 14. Analysis of variance of total scores - Part B

\begin{tabular}{|lcrrrrr|}
\hline Source & DF & Seq. SS & Adj. SS & Seq. MS & $F$ & $p$ \\
\hline rater & 9 & 7233.9 & 612.4 & 803.8 & $52.34 \dagger$ & $0.000^{*}$ \\
patient & 9 & 11087.1 & 11087.1 & 1231.9 & $80.22 \dagger$ & $0.000^{*}$ \\
error & 11 & 168.9 & 15.4 & & & \\
total & 29 & 18489.9 & & & & \\
\hline
\end{tabular}

${ }^{*} p<0.05$

$\dagger$ significant $F$ ratio 
Normal Probability Plot of the Residuals

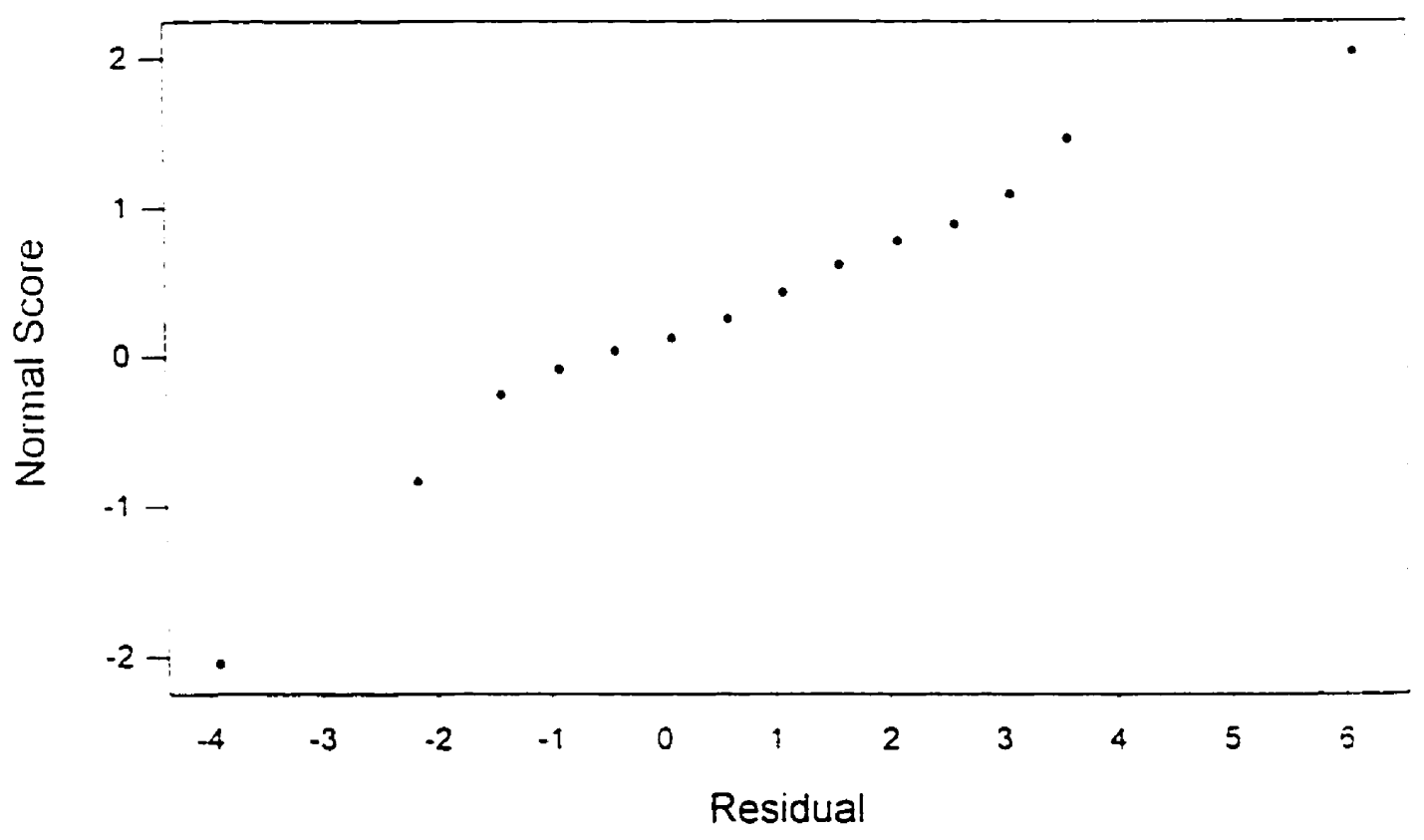

Figure 4. Normal probability plot of residuals from analysis of variance

The variance coefficients of these factors were graphed as box plots and a comparison of score dispersion (IQR) by patient and rater factors can be made in Figure 5.

Examination of the plots reveals that dispersion of the scores due to factors associated 
with the patients is greater than the dispersion due to factors that are attributed to the raters. The median of rater factors is a coefficient above 90 . The notable feature of this plot is that despite the extreme range in variability of patient factors, the raters were able to evaluate these patients with a high degree of precision as evidenced by the concentration of rater tactors in the high coefficient range

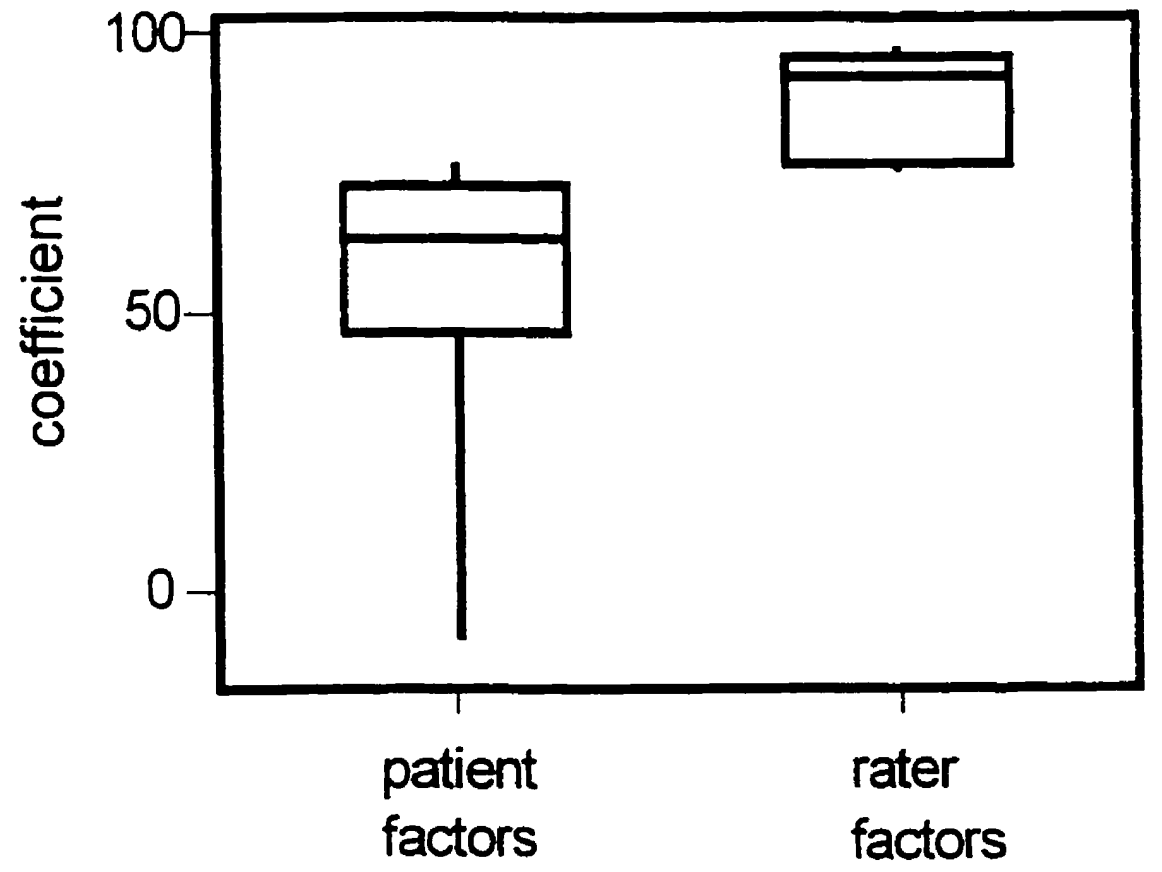

Figure 5. Box plot comparison of AMS score dispersion by patient and rater factors - Part B 
Figure 6, illustrates a comparison of rater variance by experience, with 6 of the 10 raters having no previous experience using the AMS prior to the teaching workshop. From this visual comparison, it appears that little difference in scoring can be attributed to raters' previous experience using the AMS and that the variability coefficients demonstrated by each of these groups is high.

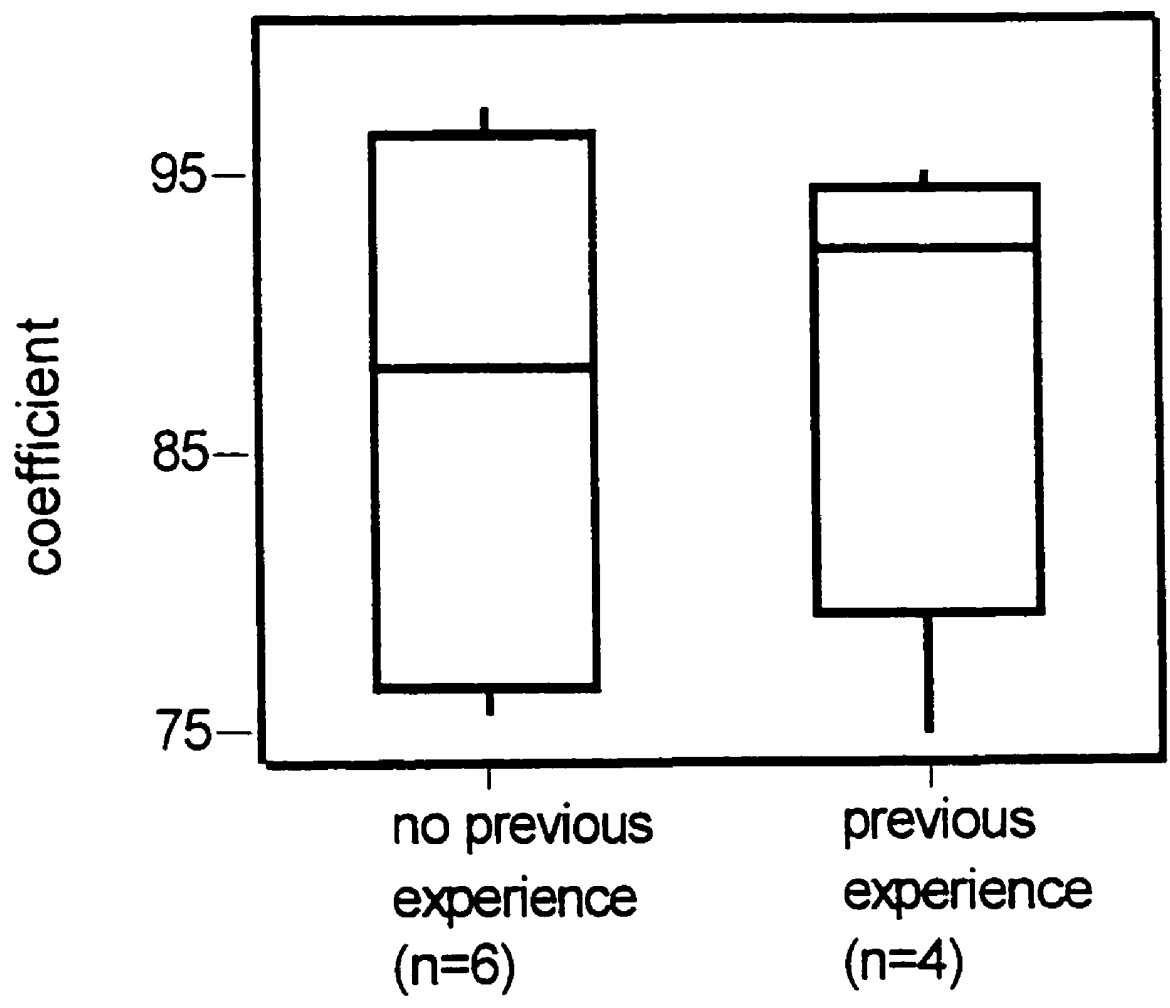

Figure 6. Box plot comparison of AMS scores by rater experience - Part B 
Principle component factor analysis of the correlation matrix is found in Table 15 and the scree plot generated from this matrix is found in Figure 7.

Table 15. Principal component factor analysis of the correlation matrix for AMS scores

\begin{tabular}{|lccc|}
\hline Variable & Factor 1 & Factor 2 & Communality \\
shoulder abduction & 0.240 & -0.850 & 0.781 \\
shoulder adduction & 0.929 & -0.079 & 0.869 \\
shoulder flexion & -0.049 & -0.906 & 0.823 \\
shoulder external rotation & 0.026 & -0.786 & 0.619 \\
shoulder internal rotation & 0.678 & -0.105 & 0.470 \\
elbow flexion & 0.416 & -0.732 & 0.708 \\
elbow extension & 0.760 & -0.403 & 0.740 \\
torearm pronation & 0.875 & -0.144 & 0.787 \\
forearm supination & 0.352 & -0.490 & 0.364 \\
wrist flexion & 0.926 & -0.084 & 0.865 \\
wrist extension & 0.752 & -0.430 & 0.751 \\
finger flexion & 0.915 & -0.066 & 0.843 \\
tinger extension & 0.859 & -0.181 & 0.770 \\
thumb flexion & 0.808 & -0.224 & 0.703 \\
thumb extension & 0.811 & -0.271 & 0.731 \\
& & & \\
Variance & 7.3322 & 3.4913 & 10.8234 \\
\hline
\end{tabular}




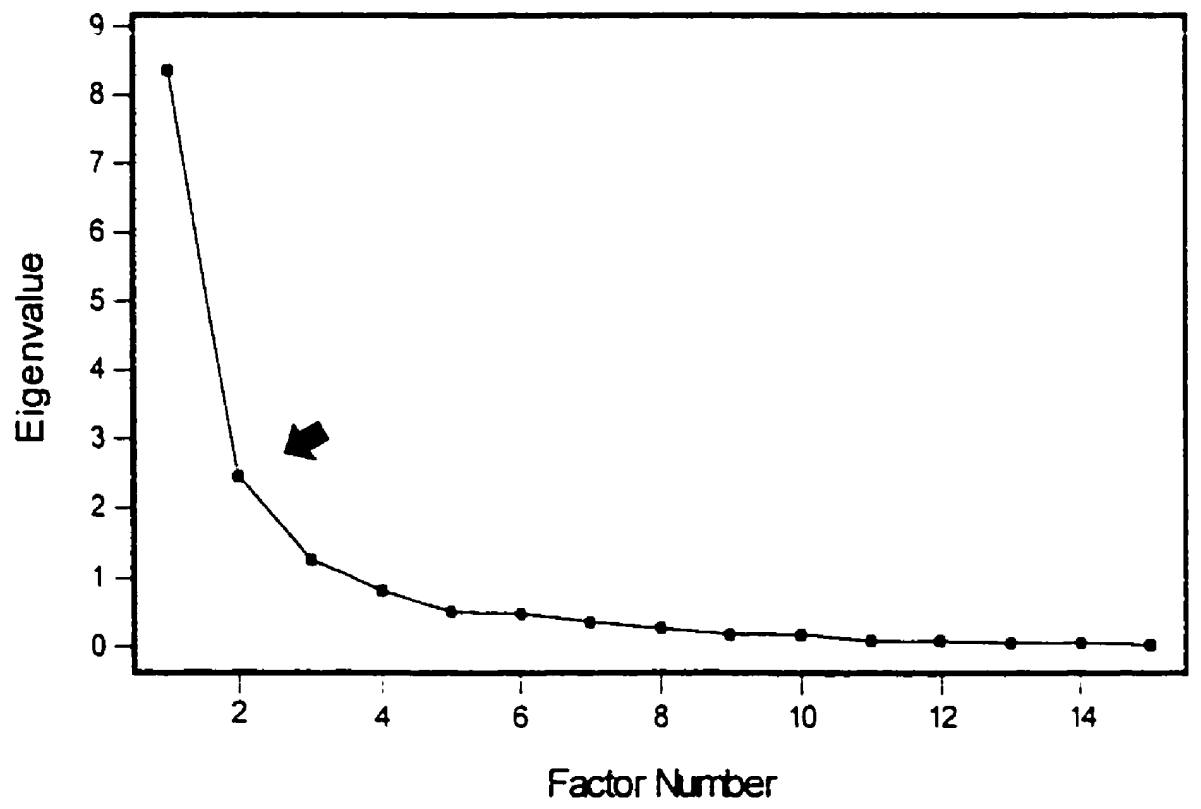

Figure 7. Scree plot of correlation matrix

Examination of the scree plot reveals that there are two factors that underlie the 15 items of the scale. This is determined by noting the point where there is a sharp break in the curve between the point where it is descending and where it levels off. 60 By examining the correlation matrix (Table 15), it is evident that 5 of the tested movements 
load onto factor 1 when a critical value of 0.5 is used to divide the factors. The five movements (shoulder abduction, shoulder flexion, shoulder extemal rotation, elbow flexion and forearm supination) when compared with a nerve root contribution chart (see Table 16) are all noted to originate from root levels $C 5, C 6, \pm C 7$ which in-turn correspond to the definition of an upper root lesion. 63

\section{Table 16. Root Contribution to Motion Tested}

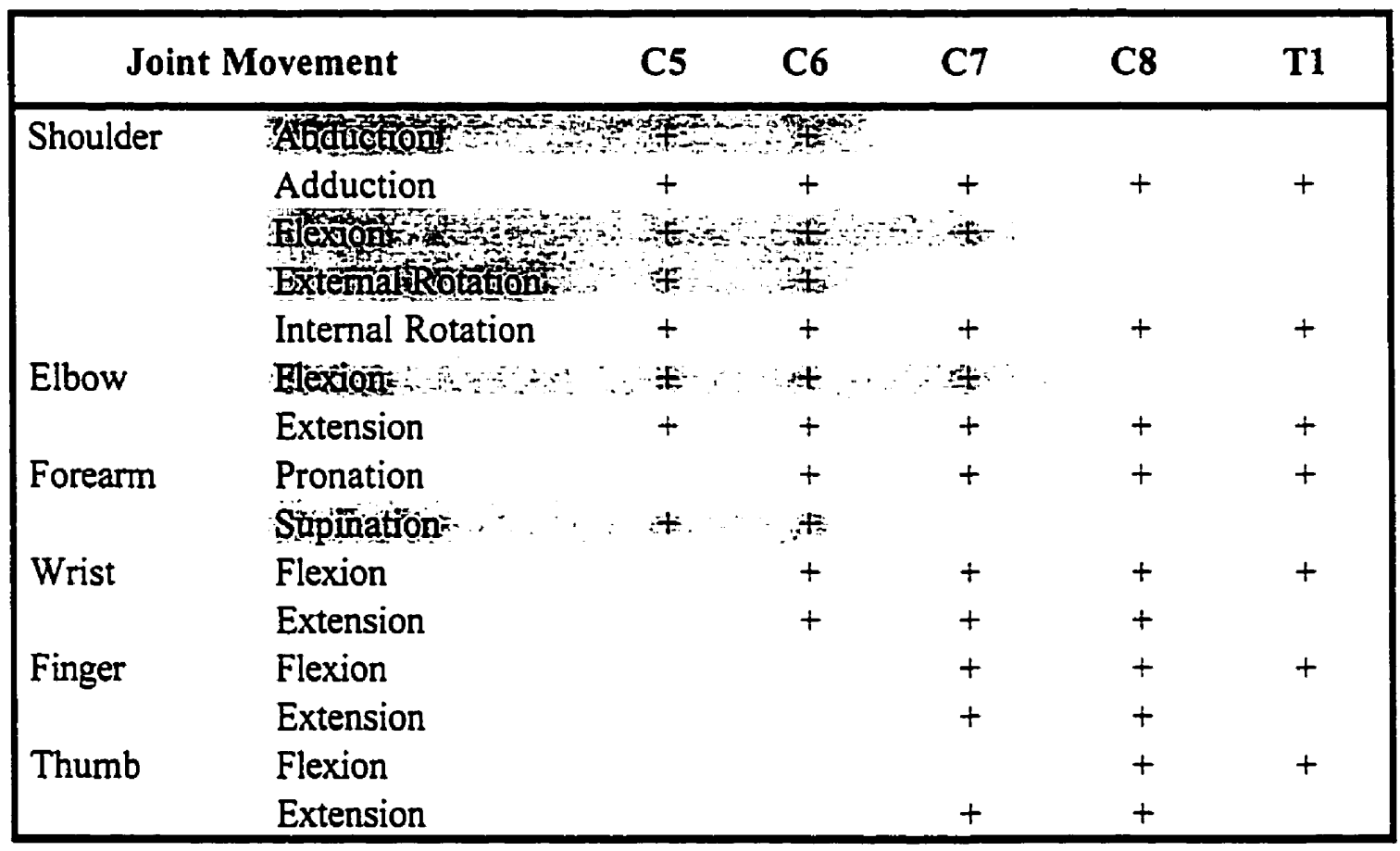

+ Indicates a significant contribution from that root to the indicated function.

From Capek L, Clarke HM, Curtis CG: Neuroma-in-continuity resection: Early outcome in obstetrical Brachial plexus palsy. Plast Reconstr Surg 102:15551562, 1998; permission pending.

\section{DISCUSSION}

Measurement is the underlying basis of scientific investigation and the presise measurement of complex clinical phenomena is one of the challenges of clinical and 
surgical research. 64 Consensus regarding a standardized method for evaluating motor power in infants with obstetrical brachial plexus palsy is yet to be established. In order to gain proper understanding of the natural history of OBPP and to design valid outcome studies, a consistent method of evaluation of upper extremity function must be used which is independent of the patient's verbal comprehension and ability to cooperate voluntarily. This method of evaluation should uphold standards of appraisal such as reliability and validity.

\section{EXISTING SCALES}

Various systems for quantifying motor power in the upper extremities of infants with OBPP have been described. 34.35 .40 .42 .47 None of the systems have had reported validity or reliability testing to date.

\section{Medical Research Council Scale}

The MRC system of manual muscle testing although reliable for examination of motor power in adults, 65,66 is not suited for use with infants. This test requires that the patient understand the nature of the examination so that full range of motion and voluntary power against resistance can be demonstrated. Infants are unable to comprehend verbal commands and cannot cooperate in a manner that will show full power against force. 


\section{Gilbert and Tassin Scale}

Simplification of the 6-point (0-5) MRC scale by Gilbert and Tassin, ${ }^{40}$ to a 4-point grading system (M0-M3), although practical in design, severely limits the ability of the scale to discriminate motor recovery. All movements that are partial in nature are classified as M2. This grade covers a wide range of incomplete movements, from slight movement with gravity eliminated to almost full range of movement against gravity. Scores in this category will fail to differentiate improvements in partial movement over time and will not distinguish between functional and non-functional movements.

The discriminative ability of a scale is dependent on the number of categories that are used. Nishisato and Torii ${ }^{67}$ have shown that for reliability coefticients in the range normally encountered. from 0.4 to 0.9 , the reliability drops as fewer categories are used. Streiner and Norman 68 have suggested that the minimum number of categories used by raters should be in the region of 5 to 7 in order to maximize the precision of a scale.

\section{Score of 10 Scale}

The "Score of 10 " system of sequelae prediction as described by Chuang et al. 47 has a number of limitations. The aims of this evaluation system were to determine the relationship between early and late obstetrical brachial plexus palsy, to predict the progressive changes that take place with aging and to propose possible reconstructive procedures. Neither scoring procedures either for early presentation or late outcome are 
validated nor has correlation between the two measures been established. Overall this system is difficult to understand. It is unclear how and when this tool is to be applied.

Impairment Scales

Similar limitations are noted with the outcome study as reported by Eng et al. 34 The initial and follow-up impairment scales that were used to classify function have not been reported to have measures of validity or reliability associated with them. This study was also conducted on the basis of a retrospective chart review.

Active Movement Scale

The Active Movement Scale is a tool that has been developed in response to the limitations of scales that are currently in use. It offers a number of advantages over other scales:

1. It can be used to grade movement in the entire upper extremities of newborns, infants and young children. The scale relies solely on the observation of active limb segment movement without and against gravity. The assignment of grades is achieved by observing upper extremity movement of the infant in three positions: supine, sidelying and sitting. Evaluation of movement in any of these positions can readily be observed with newborns. 
2. It does not require the child to perform tasks on command. Unlike the MRC or Mallet Scales where verbal instructions are required to specify the desired movement or response, evaluation of active movement using the AMS does not necessitate the achievement of a level of understanding or cooperation in order to permit the use of each grade of the scale. Grades are assigned while watching the child at play in various positions against gravity.

3. It uses gravity as a standard throughout the entire scale. Some MRC grades rely largely on an examiner's judgement. For example, an examiner's subjective assessment of the amount of resistance applied is inherent in the scoring criteria for MRC grades 4 and 5 . In contrast. the grading criteria for AMS scores have greater objectivity because an examiner uses gravity as a standard to assign scores within the entire scale.

4. Overall joint movements are evaluated in contrast to individual muscle testing. Manual muscle testing tools such as the MRC scale were designed to provide a system for individual muscle strength grading. An examiner relies on personal experience and skill to palpate muscles, detect substitution and properly stabilize the patient. Muscles in the upper extremities of newborns are so small that discrimination of individual muscle contractions can be impossible. Examination of joint movement in infants can be readily performed and provides an overall sense of function of the limb. 
5. Smaller changes in movement can potentially be detected. Although the Gilbert and Tassin grading scale is the only other practical tool for evaluating upper extremity motor power in infants, it only provides a single score for partial movement (M2). The AMS has 5 categories for grading partial movement (grades 2 to 6) which greatly increases the ability of the scale to detect partial movement. The sensitivity of the AMS is thus significantly higher than the $\mathrm{M} 0-\mathrm{M} 3$ scale.

6. It can be used for the entire life of a child. The observation of active movement without and against gravity allows the AMS to be used as an evaluative tool for the lifetime of a subject. This teature of the AMS lends itself as an ideal tool for recording the natural history of obstetrical brachial plexus palsy.

7. It can be applied before and after surgery. Pre and post-operative data can be collected using the AMS regardless of the age or condition of the patient. Unlike the impairment scales reported by Eng et al. and Chuang et al., the AMS can be used as an outcome measure to determine the effectiveness of brachial plexus reconstructive surgery.

8. It allows for direct comparison of paired data to facilitate statistical analysis. The ordinal construct of the AMS permits the use of more rigorous forms of statistical analysis as compared to nominal scales (Mallet, descriptive scales). The ability to 
analyze paired AMS data makes this an appropriate tool for studying medical and surgical interventions for patients with OBPP.

The 8-point construct of this scale (grades from 0 to 7 ) maximizes the potential for precision and reliability of measurement. Five scores that categorize less than full movement against gravity (grades 2-6), allow tor the discrimination of changes in partial movement over time. The Gilbert and Tassin scale assign a single grade for partial movement (M2). Within the AMS grades of partial movement, there is the possibility of distinguishing movements that suggest poor recovery (grades 2-5) or useful function (grade 6). For example, a patient with greater than half range of elbow flexion against gravity (score of 6 ) may potentially have greater function of elbow flexion than a patient that can only flex the elbow less than half range with gravity eliminated (score of 2). In both these situations, a patient would score M2 using the Gilbert and Tassin scale. No assumptions regarding functional potential can be made from this grade.

The Brachial Plexus Clinic at The Hospital for Sick Children has been using the AMS as an evaluative tool for infants with OBPP for the last 9 years. To date over 4,100 assessments of over 600 children have been recorded with this system in a single database. Our clinical impression of this tool is that it is a highly practical evaluative system that facilitates rapid and objective measurement of movement in infants with OBPP. Changes in motor power over time are readily apparent by scanning the patients' 
flow sheet. Localization of the lesion can easily be determined by examining an individual assessment.

\section{RELIABILITY}

The essence of reliability is the amount of error that is present in a set of scores and the amount of error in a score is directly related to the variability of factors that are associated with it. 68 Three sources of variability that can account for an unreliable measurement are the patient. the procedure. and the clinician. 69,70

With numerous factors affecting the overall reliability of a tool. there is no single analytical approach that can. in itself, define all aspects of error and variability in a measure. Separate coefticients that address different facets can be obtained and applied to relevant situations. 56 We have therefore conducted two experiments in an attempt to source various components of measurement error and variation associated with the AMS. Specifically. Part A of this work was designed to consider rater error and Part B was constructed to measure variability associated with patients and raters. Post hoc analysis of the data in Part B provides evidence as to the content validity of the AMS for the evaluation of infants with obstetrical brachial plexus lesions. 


\section{PART A}

The results of the inter-rater reliability study show that the AMS is a reliable scale for the evaluation of infants up to one year of age with OBPP when used by two experienced, physical therapist raters. Although the overall kappa statistic of the scale was 0.51 when controlling for agreement by chance alone, the overall quadratic weighted kappa coefficient of 0.89 indicated that the raters scores were close when there was a discrepancy. The majority of 15 individually tested movements were in the excellent category of agreement when analyzed using quadratic-weighted kappa. The advantage of using the quadratic weighted kappa measure is that it is exactly identical to the intraclass correlation coefticient (ICC) therefore allowing comparison with other kappa and ICC results. 60

Results of our previous work have demonstrated that 5 movements of the upper extremity (elbow flexion, elbow, wrist, finger and thumb extension) when combined into a test score, are the best predictors of final outcome of OBPP patients at 3 months of age. 20 Four of these 5 movements had excellent agreement and one movement (thumb extension) had substantial agreement when examined in this current analysis. The results of this study provide additional support for the use of these movements in the predictive test score as it is now known that they can be measured with a high degree of reliability. 


\section{Limitations of Part A}

The most obvious limitations of Part A was that only two raters, both experienced in using the AMS, were used to collect the data and that the degree of variation within the patient and rater samples was unknown. Although the overall error associated with the two raters was low, it is unclear what the true source of error was. Part B of this work was designed to address these limitations by examining the effect of multiple raters with differing amounts of experience using the AMS on the dispersion of scores of a randomized sample of patients.

\section{PART B}

The second part of the study demonstrated that patient factors clearly accounted for more variability in AMS scores than rater factors. The rater factors were narrowly dispersed with a median variance coefficient above 90 . From these results we can conclude that rater precision was high when evaluating patients with extremes in variability and that the AMS was a reliable tool.

This study also suggested that rater's previous experience with the AMS did not account for significantly higher reliability in scores when compared to inexperienced raters. Educational preparation of the raters in the application of the AMS may have accounted for the parity that was demonstrated between experienced and inexperienced rater's scoring ability. The provision of detailed guidelines for the use of this scale may also have contributed to the accuracy of the rater's results. 
Post hoc factor analysis of the results identified two sources of patterns of injury that were associated with the scores. The two sources corresponded with features related to upper root lesions $(\mathrm{C} 5, \mathrm{C} 6 \pm \mathrm{C} 7)$ and total plexus lesions $(\mathrm{C} 5-\mathrm{T} 1)$. The matching of physical damage with the pattern of scores provides a strong argument for content validity of the AMS. With content validity being defined as the degree to which the items in an instrument adequately reflect the content domain being measured ${ }^{56}$. the AMS demonstrates content validity by correctly specifying the underlying sources of patterns of injury in OBPP.

\section{Limitations of Part $B$}

The intent of this experiment was to estimate variability and compare variation associated with raters and patients. We believe that 30 evaluations obtained from a randomized sample of 10 patients were sufficient to yield useful information about interrater variability and patient variability. With a limited patient sample size, it was impossible to further define what the exact sources of patient error were - on these we must speculate. Sources of error that may have been associated with patient's are: fatigue (varying levels of wakefulness between or within assessments), interest (varying levels of attention to motivational cues or objects), anxiety (differing reactions to strangers), age (factors associated with development) and level of lesion (degrees of paralysis).

This study did not examine the reliability of raters who did not have the experience of participating in a teaching workshop. It remains undetermined whether the reliability of 
rater's scores is dependent upon skills and knowledge acquired from attending the workshop or whether these are skills that can be achieved through independent learning.

Limitations of .AMS

The AMS is not able to measure true power in the upper extremities of infants with motor weakness. Evaluation of active range of motion without resistance provides only partial quantification of available motor strength. There is no currently available instrument that can measure true muscle power in infants.

The sensitivity of the AMS also remains questionable. One of the criteria for determining whether an infant has had useful motor return in the upper extremity is to evaluate the amount of elbow tlexion that can be demonstrated at nine months of age. 21 Although a grade of 6 for elbow flexion (greater than half range of motion against gravity) suggests useful motor return, this score does not necessarily reflect useful functional movement. For example, a score of 6 may or may not represent sufficient elbow flexion for a child to independently bring a cookie to the mouth. The "cookie test" is an evaluative method that has been developed in the Brachial Plexus Clinic at HSC to help further define the functional range of elbow flexion when a score of 6 is achieved. At the age of nine months, a child with a score of 6 for elbow flexion who can bring a cookie to the mouth is not a candidate for surgery. In contrast, child with a score of 6 that cannot raise the cookie to the mouth will be recommended for surgical brachial plexus reconstruction. 


\section{Future Study}

The true reliability of the AMS will never be known as it is impossible to determine to what extent the observed scores vary from true AMS scores (a measure that can never be calculated). Future investigations however, should serve to define additional sources of error that are associated with this tool. Evidence from our second study indicates that sources of error that appear related to this instrument are predominantly patient related. Experiments that examine potential sources of scoring discrepancy such as patient age. level of lesion and operative intervention may help to further define the reliability of the AMS and may aid in retining the guidelines for the use of this tool.

The reliability of raters with clinical expertise in areas other than paediatric physiotherapy is another potential source of investigation. Levels of reliability between and within other medical professionals that communly evaluate infants with OBPP such as surgeons, occupational therapists and nurses remains unanswered.

Future investigation should also compare the reliability of raters that receive instruction in use of the AMS using a direct teaching approach versus independent learning.

The predictive ability of the AMS although reported in a previous study, 20 requires additional consideration. Examination of the tool's ability to predict the patients that would be appropriate for early surgical intervention in cases where it is presently unclear would be of benefit. 


\section{CUNCLUSION}

We have investigated the reliability of the Active Movement Scale for the evaluation of infants with obstetrical brachial plexus palsy by examining sources of error in two studies. From these experiments we can conclude that error is low in raters who have been trained in the use of the scale and that patient-related factors appear to account for the majority of variance between and within scores. Although error attributed to the scale itself was not studied directly, factor analysis of the results provides evidence for content validity of the Active Movement Scale.

The clinical significance of these tindings is that evidence presently exists to support the use of the Active Movement Scale as an evaluative tool for infants with upper extremity paralysis. This instrument has signiticant potential tor use in future studies directed at defining the natural history of obstetrical brachial plexus palsy, deciding on appropriate treatment options and measuring treatment outcomes. It is hoped that evidence for the reliability of this tool will lead to a consensus regarding a standardized method of evaluation for infants with obstetrical brachial plexus palsy. 


\section{REFERENCES}

1. Leffert R. Brachial Plexus Injuries. New York: Churchill Livingstone; 1985.

2. Moore K. Clinically Oriented Anatomy. Baltimore: Williams \& Wilkins; 1985.

3. Smellie W. Collection of cases and observation in midwifery. vol. 2. 4 ed. London; i768.

4. Duchenne G. De l'Électricsation localisée et de son application à la pathologie et à la thérapeutique par courants induits et par courants galvaniques interrompus et continus. Third ed. Paris: Librairie J.B. Baillière et fils: 1872.

5. Erb W. Über eine eigenthümliche lucalisation von lähmengen in plexus brachialis. Verhandl Naturhist Med 1874:2:130.

6. Klumpke A. Contribution à l'étude des paralysies radiculaires du plexus brachial. Rev Méd 1885;5:739.

7. Sever J. Obstetric paralysis. Am J Dis Child 1916:12:541-578.

8. Jennett R. Tarby T, Kreinick C. Brachial plexus palsy: An old problem revisited. Am J Obstet Gynecol 1992;166:1673.

9. Gilbert A, Razaboni R. Amar-Khodja S. Indications and results of brachial plexus surgery in obstetrical palsy. Orthop Clin North Am 1988:19:91-105.

10. Brown LB. Review of obstetrical palsies: Nonoperative treatment. Clin Plast Surg 1984:11:181-187.

11. Gilbert A. Long-term evaluation of brachial plexus surgery in obstetrical palsy. Hand Clin 1995;11:583-595. 
12. Levine M, Holryode J, Woods JJ, Siddiqui T, MacHenry S, Miodovnik M. Birth Trauma: incidence and predisposing factors. Obstet Gynecol 1984;63:792-795.

13. McFarland L, Roaskin M, Daling J, Benedetti J. Erb/Duchenne palsy: a consequence of fetal macrosomia and method of delivery. Obstet Gynecol 1986:68:78+-788.

14. Metaizeau J, Gayet C. Plenat F. Les lésions obstétricales du plexus brachial. Chir Pédiatr 1979:20:159.

15. Painter M. Brachial plexus injuries in neonates. Intern Pediatr 1988:3:120-124.

16. Gordon M, Rich H, Deutschberger J, Green M. The immediate and long-term outcome of obstetrical birth trauma. Am J Obstet Gynecol 1973:117:51-56.

17. Humphreys D. Snyder R. Turnell R. Erb's palsy in Saskatchewan: Incidence. associated risk factors. and outcome. Sask Med J 1995:6:6-9.

18. Alanen M, Ryöppy S. Varho T. Twenty-six early operations in brachial birth palsy. Z Kinderchir 1990;45:136-139.

19. Jackson ST. Hoffer MM, Parrish N. Brachial plexus palsy in the newborn. J Bone Joint Surg 1988:70:1217.

20. Michelow BJ, Clarke HM, Curtis CG, Zuker RM, Seifu Y. Andrews DF. The natural history of obstetrical brachial plexus palsy. Plast Reconst Surg 1994;93:675-680.

21. Clarke HM. Curtis CG. An approach to obstetrical brachial plexus injuries. Hand Clin 1995; 11:563-581. 
22. Tachdjian MO. Pediatric Orthopedics. vol. 3. 2nd ed. Philadelphia: W.B. Saunders Company; 1990.

23. Salter RB. Textbook of disorders and injuries of the musculoskeletal system. third ed. Philadelphia: Lippincott Williams \& Wilkins; 1999.

24. Greenwald AG, Schute PC, Shiveley LJ. Brachial plexus birth palsy: A I0-year report on the incidence and prognosis. J Pediatr Orthop 1984;4:689.

25. Boome R. Indications and timing of surgery tor obstetric brachial plexus palsies. In: Vastamäki, editor. Current Trends In Hand Surgery: Proceedings of the 6th Congress of the International Federation of Societies For Surgery of the Hand. Helsinki. Finland: Elsevier: 1995.

26. Capek L. Clarke HM, Curtis CG. Neuroma -in-continuity resection: Early outcome in obstetrical brachial plexus palsy. Plast Reconstr Surg 1998:102:15551562.

27. Carlstedt $T$. Strömbeck C. Surgical vs. conservative treatment of obstetrical brachial plexus palsy: A preliminary study. In: Vastamäki M, editor. Current Trends In Hand Surgery: Proceedings of the 6th International Congress of the International Federation of Societies for Surgery of the Hand (IFSSH). Helsinki, Finland: Elsevier; 1995.

28. Clarke H, Al-Qattan M, Curtis C, Zuker R. Obstetrical brachial plexus palsy: Results following neurolysis of conducting neuromas-in-continuity. Plast Reconstr Surg 1996;97:974-982. 
29. Piatt JHJ. Neurosurgical management of birth injuries of the brachial plexus. Neurosurg Clin North Am 1991;2:175.

30. Kawabata H, Kawai H, Masatomi T. Yasui N. Accessory nerve neurotization in infants with brachial plexus birth palsy. Microsurgery 1994;15:768-772.

31. Laurent J, Lee R, Shenaq S, Parke J, Solis I, Kowalik L. Neurosurgical correction of upper brachial plexus birth injuries. J Neurosurg 1993;79:197-203.

32. Slooff A. Obstetric brachial plexus lesions and their neurosurgical treatment. Microsurgery 1995;16:30-34.

33. Slooff BA. Blaauw G. Obstetric brachial plexus lesions in children born in a breech presentation and their neurosurgical treatment. In: Vastamäki M. editor. Current Trends In Hand Surgery: Proceedings of the 6th Congress of the International Federation of Societies for Surgery of the Hand (IFSSH). Helsinki, Finland: Elsevier; 1995. p. 269-273.

34. Eng G, Binder H, Getson P, O'Donnell R. Obstetrical brachial plexus palsy (OBPP) outcome with conservative management. Muscle Nerve 1996;19:884-891.

35. Aids to the Investigation of Peripheral Nerve Injuries. In: . London: His Majesty's Stationary Office; 1943. p. 48.

36. Sherburn E, Kaplan S, Kaufman B, Noetzel M, Park T. Outcome of surgically treated birth-related brachial plexus injuries in twenty cases. Ped Neurosurg $1997 ; 27: 19-27$.

37. Solonen K, Telaranta T, Ryöppy S. Early reconstruction of birth injuries of the brachial plexus. J Pediat Orthop 1981;1:367-370. 
38. Shenaq S, Berzin E, Lee R, Laurent J, Nath R, Nelson M. Brachial plexus birth injuries and current management. Clin Plast Surg 1998;25:527-536.

39. Sjöberg I, Erichs K, Bjerre I. Cause and effect of obstetric (neonatal) brachial plexus palsy. Acta Pædiatr Scand 1988;77:357-364.

40. Gilbert A, Tassin J-L. Obstetrical palsy: A clinical, pathologic and surgical review. In: Terzis JK. editor. Microreconstruction of Nerve Injuries. Philadelphia: WB Saunders: 1987. p. 529.

41. Hentz V. Meyer R. Brachial plexus microsurgery in children. Microsurgery 1991:12:175-185.

+2. Mallett J. Paralysie obstétricale du plexus brachial. Traitement des séquelles. Primauté du traitment de l'épaule - Méthode d'expression des résultats. Rev Chir Orthop 1972:58(suppl. 1):166-168.

43. Duclos L, Gilbert A. Obstetrical palsy: Early treatment and secondary procedures. Ann Acad Med 1995;26:841-845.

44. Gilbert A, Brockman R, Carlioz H. Surgical treatment of brachial plexus birth palsy. Clin Orthop Rel Res 1991;264:39-47.

45. Gilbert A, Whitaker I. Obstetrical brachial plexus lesions. J Hand Surg $[\mathrm{Br}]$ 1991;16B:489-491.

46. Mever R. Treatment of adult and obstetrical brachial plexus injuries. Orthopedics 1986;9:899-903.

47. Chuang DCC, Ma H-S, Wei F-C. A new evaluation system to predict the sequale of late obstetric brachial plexus palsy. Plast Reconstr Surg 1998;101:673-685. 
48. Hunt D. Surgical management of brachial plexus birth injuries. Devel Med \& Child Neurol 1988;30:823-828.

49. Jahnke A, Bovill D, McCarroll H, James P, Ashley R. Persistent brachial plexus birth palsies. J Pediatr Orthop 1991:11:533-537.

50. Kwai H, Yamamoto K, Murase T, Shibuya R, Masatomi T, Kawabata H, et al. Brachial birth palsy - Cervical myelography and early brachial plexus surgery. In: Vastamäki M. editor. Current Trends In Hand Surgery: Proceedings of the 6th International Federation of Societies for Surgery of the Hand. Helsinki. Finland: Elsevier: 1995.

51. Kawabata H. Masada K. Tsuyuguchi Y, Kawai H, Ono K. Tada K. Early microsurgical reconstruction in birth palsy. Clin Orthop Rel Res 1987:215:233$2+2$.

52. Al-Qattan M. The first multi-disiplinary obstetrical brachial plexus clinic in Saudi Arabia. J Hand Surg [Br] 1996:2 lB:124-125.

53. Norton E, Developmental muscular torticollis and brachial plexus injury. In: Campbell S, editor. Physical Therapy for Children, second ed. Philadelphia: W. B. Saunders; 2000.

54. Shepherd R. Brachial plexus injury. In: Campbell S, editor. Pediatric Neurologic Physical Therapy. New York: Churchill Livingstone: 1984. p. [41-168.

55. Donner A. Eliasziw M. Sample size requirements for reliability studies. Statistics In Medicine 1987;6:441-448. 
56. Portney L, Watkins M. Foundations of Clinical Research: Applications To Practice. Stamford: Appleton and Lange; 1993.

57. Cohen J. Coefficient of agreement for nominal scales. Educ Psychol Meas $1960 ; 20: 37$.

58. Landis J, Koch G. The measurement of observer agreement for categorical data. Biometrics 1977:33:159-174.

59. Cohen J. Weighted kappa: Nominal scale agreement with provision for scaled disagreement or partial credit. Psychol Bull 1968;70:213.

60. Norman GR. Streiner DL. Biostatistics. The Bare Essentials. St. Louis: Mosby. Inc.: 1994.

61. Byrkit D. Statistics Today: A comprehensive introduction. Menlo Park: Benjamin Cummings: 1987.

62. Altman D. Practical Statistics For Medical Research. London: Chapman and Hall: 1991.

63. Terzis J, Liberson W, Levine R. Our Experience In Obstetrical Brachial Plexus Palsy. Philadelphia: Saunders; 1987.

64. Wright J. McLeod R, Lossing A. Walters B, Hu X. Measurement in surgical clinical research. Surgery 1996;119:241-244.

65. Iddings D, Smith L, Spencer W. Muscle testing: Part 2. Reliability in clinical use. Phys Ther Rev 1961;41:249-256. 
66. Wadsworth C, Krishnan R, Sear M, Harrold J, Nielsen D. Interrater reliability of manual muscle testing and hand held dynametric muscle testing. Phys Ther $1987 ; 67: 1342-1346$.

67. Nishisato $\mathrm{N}$, Torii $\mathrm{Y}$. Effects of categorizing continuous normal distributions on the product-moment correlation. Jap Psych Res 1970;13:45-49.

68. Streiner DL, Norman GR. Health Measurement Scales, A Practical Guide To Their Development And Use. Second ed. New York: Oxford University Press Inc.: 1995.

69. Sackett D. Clinical disagreement: I. How often it occurs and why. Can Med Assoc J 1980:123:499-504.

70. Feinstein A. Clinimetrics. New Haven: Yale University Press: 1987. 


\section{APPENDICES}

APPENDIX I: GUIDELINES FOR USE OF THE ACTIVE MOVEMENT SCALE

Guidelines For Use Of The Active Movement Scale

\section{Rules For Assigning Grades:}

1. A score of + must be achieved (tull range of motion with gravity eliminated) before a higher score can be assigned. This clarifies scoring when limited movement is present both with gravity eliminated and against gravity.

2. Movement grades are assigned within the available range of passive motion. If a flexion contracture is present at the elbow, for example. full range of extension is scored if the elbow can be extended to the limits of the contracture.

3. Movement is assessed within the age-appropriate range of motion, with the uninvolved contralateral limb used as a control to estimate the extent of available normal range.

4. Extension of the digits is assessed at the metacarpophalangeal joints. Flexion of the digits is evaluated by observing the distance at rest between the finger-tips and the palm and then observing the active motion as a fraction of that distance, both with and without gravity.

5. Digital flexion or extension is given a single grade by using the movement score of the best digit. If the index finger scores a grade of 7 for flexion and the other digits score 2, for example, then the finger flexion score is 7 . 


\section{Method of Application:}

The Active Movement Scale should be administered with the upper body and arms of the infant exposed. Ideally, the child is placed on a flat, firm surface where her or she can move or roll. A variety of toys should be available to stimulate movement. Rattles or toys that make sounds are especially useful.

Gravity eliminated movements are assessed first to determine whether scores above 4 can be assigned. To grade shoulder tlexion. for example, the child is placed in the gravityeliminated position of side-lying with the affected arm uppermost. A rattle is placed within the child's view and moved in a way to attract attention. Tactile stimulation of the arm using the toy followed by movement of the toy in a forward direction draws attention to the arm and encourages flexion of the shoulder. The anterior deltoid region of the shoulder is palpated to detect tlickers of movement if minimal active movement is seen. If less than full range of available passive movement is obtained compared with the contralateral normal side, then a score of 3 or lower is given. If full range of forward flexion is obtained (giving a score of 4 ), the child is placed in a supported sitting position to view movement against gravity. Again the child is encouraged to reach forward for an object. An against-gravity score of 5 or more is assigned depending on the greatest range of motion observed.

In this way, all joint movements are scored atter observation in gravity-eliminated and against-gravity positions. Parents may participate in encouraging movement if a child is especially anxious with strangers. With practice, all joint movements can be graded by observation of play in three positions - supine, side-lying and sitting. 


\section{APPENDIX 2: AMS EVALUATION FORM}

\section{AMS Evaluation Form}

\section{Observation}

\section{Muscle Grade}

Gravity eliminated

No contraction

Contraction, no motion

Motion _ range

Motion $>$ range

Against gravity

Full motion

Involved side: $\mathrm{R} / \mathrm{L}$

Shoulder Abduction

Shoulder Adduction

Shoulder Flexion

Shoulder External Rotation

Shoulder Internal Rotation

Elbow Flexion

Elbow Extension

Forearm Pronation

Forearm Supination

Wrist Flexion

Wrist Extension

Finger Flexion

Finger Extension

Thumb Flexion

Thumb Extension 


\section{APPENDIX 3: CONSENT FORM FOR PARTICIPANTS}

\section{Title of Research Project:}

A Comparison Of Rater Variability And Reliability When Using The Active Movement Scale To Assess Infants With Obstetrical Brachial Plexus Injuries

\section{Investigator(s):}

Primary Investigator:

Christine Curtis, MSc(candidate), BSc.P.T.

Department of Rehabilitation Services

Co-Investigators:

Rosemary Tannock BSc.P.T., PhD

Brain \& Behavior Research Programme

Senior Scientist, Research Institute

David Andrews PhD

Department of Preventative Medicine

And Biostatistics

University of Toronto

\section{Purpose of the Research:}

Babies with birth injuries to certain nerves in the neck have muscle weakness in an arm. It is important for different health care professionals (doctors and therapists) to be able to carefully measure the amount of movement in the arms of these babies. Many important decisions about the treatment of this type of problem are made on the amount of movement in the arm and the change in movement over time. This study will help us to measure the amount of agreement that different physical therapists have in recording arm movement in babies with birth injuries. It will help us see if a scale developed at The Hospital for Sick Children (called The Active Movement Scale) is accurate. If it is, we may be able to improve the care of babies with this type of birth injury. 


\section{Description of the Research:}

The study will be on Saturday November 13,1999 in the Rehabilitation Department at the Hospital for Sick Children. Your child will have the movement of their weak arm measured three times by two different physical therapists. The movement testing will be similar to the normal check your child has during a Physiotherapy or Brachial Plexus Clinic appointment at the Hospital for Sick Children. During the measurements, your child will be undressed to the waist and comfortably positioned on a soft mat. The therapist wiil piay with your chiid and encourage them to move their arm by using different toys. You will be with your child during the whole test and may be asked to join in some of the simple play activities. The testing will be stopped at any time if requested by you. Each therapist will record their measurements on a piece of paper that will be given to the researcher at the end of the test. The measurements will take no longer than 15 minutes to finish and there will be a 15 minute break between tests for you and your child.

\section{Potential Harms, Injuries, Discomforts or Inconvenience:}

There is no known harm that can occur to your child from this study. They will not experience any discomfort in their arm during the measurements. Some children may feel anxious by being handled by unfamiliar people. You may be encouraged to join in with the play activities so that your child is not upset. You may hold or comfort your child at any time during the measurements and every effort will be made to allow for ample rest during and between the tests. We understand that participation in this study will cause the inconvenience of a weekend visit to the hospital. On site childcare will be provided for your other children if required. A small reimbursement $(\$ 40)$ will be given to you for gas and parking. You can decide not to participate in the study at any time. This will not affect the way that you or your child is treated at all.

\section{Potential Benefits:}

You or your child will not benefit directly from being part of this study. You/your child's participation will help us to develop a reliable scale for measuring movement and strength in the arms of babies with muscle weakness. This will help to provide the best care possible for children with these injuries. 


\section{Confidentiality:}

Confidentiality will be respected and no information that identifies you or your child will be released or published without consent unless required by law. For your information, the research consent form will be placed in your child's health record.

Participation:

Participation in this research is completely voluntary. If you choose not to participate, your child will continue to receive quality care at The Hospital for Sick Children. 


\section{Consent:}

"I acknowledge that the research procedures described above have been explained to me and that any questions that I have asked I have been answered to my satisfaction. I have been informed of the alternatives to participation in this study. including the right not to participate and the right to withdraw without compromising the quality of medical care at The Hospital for Sick Children for my child and for other members of my family. As well. the potential harms and discomforts have been explained to me and I also understand the benefits (if any) of participating in the research study. I know that l may ask now or in the future, any questions I have about the study or the research procedures. I have been assured that records relating to my child and $m y$ child's care will be kept confidential and that no information will be released or printed that would disclose personal identin. without my permission unless required by law: "

I hereby consent for my child to participate.

Name of Parent

Signature
Vame of person who obrained consent

Signature

Date

The person who may be contacted about this research is:

Christine Curtis who may be reached at telephone \#: (416) 813-6755 
APPENDIX 4: PATIENT PARTICIPANT QUESTIONNAIRE

Child's Name:

Sex:

Male

Female

Age:

Birth Date:

Involved Side:

Right

Left

Surgical Intervention:

No

Yes

Months of age

Study Use Only

Subject \#:

Nerve Root Involvement: Upper Total 


\section{APPENDIX 5: CONSENT FORM FOR HEALTH CARE PROFESSIONALS}

\section{Title of Research Project:}

A Comparison Of Rater Variability And Reliability When Using The Active Movement Scale To Assess Infants With Obstetrical Brachial Plexus Injuries

Investigator(s): Primary Investigator:

Christine Curtis, MSc(candidate), BSc.P.T.

Department of Rehabilitation Services

Co-Investigators:

Rosemary Tannock BSc.P.T., PhD

Howard Clarke MD, PhD

Brain \& Behavior Research Programme

Division of Plastic Surgery

Senior Scientist, Research Institute

David Andrews PhD

Department of Preventative Medicine

ChantalGraveline BSc.P.T.

And Biostatistics, University of

Toronto

MSc., PhD.

Department of Rehab.

Services

\section{Purpose of the Research:}

Infants with injuries to the nerves of the brachial plexus have motor weakness in their aftected arm. It is important for different health care professionals (doctors and therapists) to be able to accurately measure the amount of movement in the arms of babies with brachial plexus injuries. Many important decisions that are made about the treatment of children with brachial plexus injuries are based on the amount of movement in the upper extremity and the change in movement over time. Your participation in this study will help us to determine the amount of agreement that different physical therapists have in measuring movement in the arms of babies with obstetrical brachial plexus injuries when using a scale that has been developed at the Hospital for Sick Children - The Active Movement Scale. This study is the first step in determining the accuracy of this scale and may help in the development of a standardized method for evaluating babies with brachial plexus injuries. 
Description of the Research:

The study will take place in the Rehabilitation Department at the Hospital for Sick Children on Friday November 12 and Saturday November 13, 1999. You will be required to attend a workshop (approximately 3 hours in length) on the use of the Active Movement Scale. You will learn about the scale through a variety of teaching methods (didactic lecture, video presentation, practice with dolls and patient demonstrations) which will provide instruction about the scale and its application. Within 2 days of the teaching workshop you will participate in the assessment portion of the study.

On the assessment day, you will perform 3 assessments on 2 infants with obstetrical brachial plexus injuries (one patient is assessed twice, the other once). During the evaluation the child will be undressed to the waist and comfortably positioned on a soti mat. You will play with the child and encourage them to actively move their arm by using a variety of toys. The parent(s) will be present during the assessment and you may ask them to participate in some of the play activities in order to elicit desired movements. The testing will be stopped at any time if requested by the parent. You will record your findings on a piece of paper that will be given to the researcher at the end of the assessment. Each examination will take no longer than 15 minutes to complete and there will be a minimum of 15 minutes between tests to allow rest for the patient, their parent(s) and yourself.

\section{Potential Harms, Injuries, Discomforts or Inconvenience:}

There are no known harms associated with this study and infants being assessed using The Active Movement Scale will not experience any discomfort. The time commitment over 2 days (approximately 5 hours) may pose some inconvenience for you as an assessor. A small reimbursement of $\$ 40$ for parking and gas will be offered.

\section{Potential Benefits:}

You will not benefit directly from participating in this study. Your attendance in the Active Movement Scale Workshop may provide you with additiona! clinical knowledge in the assessment of obstetrical brachial plexus patients that you may not have had previously. Your participation in this study will help to contribute to the development of a reliable scale for measuring movement and strength in the affected arms of infants with obstetrical brachial plexus injuries. This will help to provide the best care possible for children with these injuries. 


\section{Confidentiality:}

Confidentiality will be respected and no information that discloses the identity of you or the subjects will be released or published without consent unless required by law. For your information, this research consent form will be kept on file by the primary investigator.

\section{Participation:}

Participation in this research is completely voluntary. You are tree to withdraw from the study at any time. 


\section{Consent:}

"I acknowledge that the research procedures described above have been explained to me and that any questions that I have asked l have been answered to my satisfaction. I have been informed of the alternatives to participation in this study, including the right not to participate and the right to withdraw without compromising the qualin of medical care at The Hospital for Sick Children for me and for other members of my family. As well. the potential harms and discomforts have been explained to me and I also understand the benefits (if any) of participating in the research study. I know that I may ask now or in the future. any questions I have about the study or the research procedures. I have been assured that records relating to me and my care will be kept confidential and that no information will be released or printed that would disclose personal identity without my. permission unless required by law."

I hereby consent to participate.

.Vame

Signature
Vame of person who obtained consent

Signature

Date

The person who mav be contacted about this research is:

Christine Curtis who may be reached at telephone \#: (416) 813-6755 
APPENDIX 6: RATER QUESTIONNAIRE

Name:

Sex:

Female

Male

Age:

Occupation:

License \#:

Years of Full Time Paediatric Employment:

Present Employer:

Experience With Active Movement Scale (prior to teaching workshop):

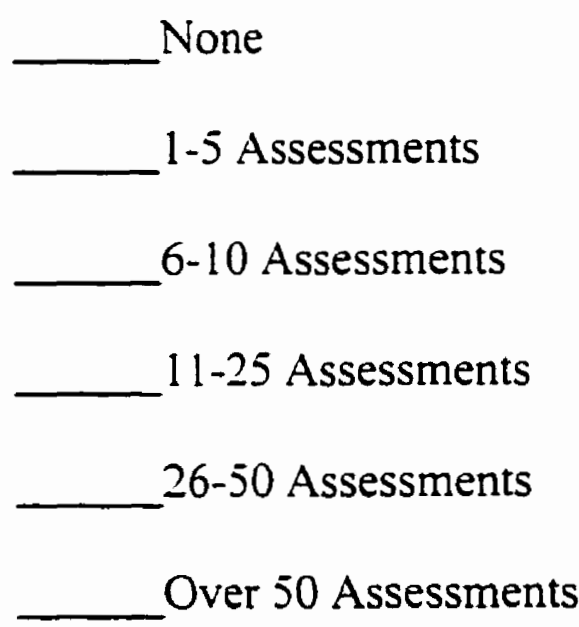

Study Use Only:

Rater \#: 